Article

\title{
Sustainable Regulation of Information Sharing with Electronic Data Interchange by a Trust-Embedded Contract
}

\author{
Guanghua Han ${ }^{1, *}$ and Ming Dong ${ }^{2}$ \\ 1 School of International and Public Affairs, Shanghai Jiao Tong University, Shanghai 200030, China \\ 2 Antai College of Economics and Management, Shanghai Jiao Tong University, Shanghai 200030, China \\ * Correspondence: hanguanghua@sjtu.edu.cn
}

Academic Editor: Marc Rosen

Received: 23 April 2017; Accepted: 31 May 2017; Published: 6 June 2017

\begin{abstract}
This paper studies the risks in demand information sharing applications by electronic soft-orders using electronic data interchange (EDI) systems in e-commerce and aims to suggest a sustainable regulation mechanism with a trust-embedded contract. In a supply chain with one retailer and one supplier, the retailer solicits private forecasted demand and places soft-orders via EDI to the supplier. To ensure abundant supply, the retailer has an incentive to inflate her soft-orders, which potentially harms the credible information sharing and sustainability of business cooperation. Normally, the degree to which the supplier relies on the retailer's order information is specified by trust, which is evaluated according to the retailer's reputation and supplier's intuition in this study. Based on standard game theory, we find that both the retailer's order and the quantity of supplier prepared materials are independent of the retailer's forecast. Therefore, EDI based information sharing in e-commerce without a regulation mechanism leads to inefficient demand information sharing. Since both the supplier and retailer are proved to faces huge of potential profit losses due to the failure of information sharing, the commerce by EDI based information sharing is full of risk and unsustainable. Therefore, a regulation mechanism that leaded by the retailer is proposed to establish 'win-win' sustainable cooperation. Numerical experiments highlight the value of trust, the impact of reputation and intuition in decisions, and the effectiveness of the regulation mechanism by a cost-sharing contract.
\end{abstract}

Keywords: electronic soft-order; information sharing; trust; regulation

\section{Introduction}

In e-commerce practices, retailers usually follow initiatives such as EDI (electronic data interchange) to share demand information to suppliers by soft-orders [1]. These costless, non-binding and nonverifiable type of orders are employed to quickly and directly transfer market information to suppliers [2]. In the last decades, buyers, with the help of modern technologies, can shop across many different channels, including physical store, laptop, smartphones, among others [3]. In order to meet customers' requirements in the competitive circumstance, companies tend to align all of their channels in a new synchronized operating model called omni-channel retailing. The EDI systems, as well as EPOS (Electronic Point of Sale) systems, provides the valuable historical data to make quick cooperative operations in omni-channel retailing strategy [4]. Since EDI applications provide less input errors, faster response time, standardized information and improved pay cycle, information sharing via EDI systems is favorite by many firms. For example, it is reported that more than $41 \%$ of Asia Pacific firms have adopted EDI systems to transmit their soft-orders since 2008 [5]. 
Currently, strategic information transmission and designing of information sharing mechanism through soft-orders are important subjects of studies [6]. In the information sharing process, the suppliers evaluate information from soft-orders mainly based on personal beliefs, which are usually referred to as trust $[7,8]$. Considering a supply chain with a retailer (she) and a supplier (he), the retailer firstly places a soft-order after she forecasts the market demand. After that, the supplier refers to this order and historical demand information to prepare his production. However, fully relying on a soft-order also usually leads to a great risk of over production because the order is unbounded and the retailer has an incentive to over-order products for abundant supply [9]. In some situations, the supplier completely ignores the shared information and deems all communications to be meaningless [10]. As a result, when the supplier's belief on demand is apart from the real market demand, there exists big gap between his outputted product quantity and the demand. Thus, demand is not able to be fully satisfied and both supply partners face opportunity losses. Therefore, EDI systems without regulation mechanism possibly lead to failure of information sharing and 'lose-lose' unsustainable trades. Meanwhile, surplus supply is beneficial to the retailer, she is willing to encourage the supplier to produce more product by sharing a percentage of production cost for surplus supply. In return, the supplier's perceived risk of over-production is mitigated due to the retailer's shared cost and production of more products. Thus, both the supplier and retailer are motivated to cooperate in a coordination mechanism. In this study, we suggest a supply chain regulation mechanism to coordinate the supply chain and improve the sustainability of the cooperation between business partners.

Although trust is able to specify the supplier's willingness to rely on shared information [11], trust is usually evaluated only based on the trustee's reputation (e.g., past experience or peer recommendation [12]). However, because trust is a psychological state composed of the intention to accept vulnerability based on positive expectations of the intentions or behaviour of another, the trust is also directly affected by trustor's personal intuition [13]. In this paper, we propose a model in which the influence of intuition is estimated by intuition gap, which is defined as the difference between the retailer-ordered quantity and the supplier's initial belief on market demand. Therefore, a trust-evaluation model considering the retailer's reputation and the supplier's intuition is formulated.

The main contexts can be summarised as follows: In Section 2, we provide a literature review; Section 3 gives a trust-quantifying model; In Section 4, we propose a trust-embedded order strategy via cost-sharing contract; In Section 5, some managerial insights are found using numerical experiments; Section 6 summarises and concludes the paper.

\section{Related Works}

In the past few years, great emphasis has been paid on operation management under uncertain circumstance. The supply chain uncertainties results from many resources, such as demand forecast, consumer requirements and delivery time, and so on [14]. This study is motivated uncertainty of demand information sharing and subsequent moral hazard in supply chain commerce transactions. Thus, uncertain in demand forces companies to applying IT technologies (e.g., collaborative planning, collaborative forecasting and replenishment, CPFR) to enhance their ability of forecast and strategically control their production/purchasing schedule with many optimizing methods [15]. However, full scope of a firm's actions (for example, marketing demand forecast) is not observable, or at least unverifiable, by his partners in their cooperative business in many practical situations. Supply chain participator often makes decisions under uncertain circumstance with less reliable information. Generally, uncertainty management is very helpful to achieve optimal supply chain performances [16].

Double Marginalization effect, which means each party maximizes its own profit by making use of its private forecasting information, indicates that reducing uncertainty by information sharing is a hard task. Coordinating the supply chain may help uncertainty management in the information asymmetry circumstance [17]. Actually, mutually agreeable contracts among players are often investigated in the presence of asymmetric or incomplete information scenarios to enhance information sharing and reduce decision uncertainty from economical and operational perspective [18]. For better performance 
of the contracts, some strategies like review-trigger [19] and late penalties [20] are widely used to incentivize all players. Note that multi-sided moral hazard occurs when more than one player hold unobservable information in a transaction. Thus, contracts on multi-sided moral hazard have begun to be theoretically discussed in various literatures. For example, Bhattacharyya and Lafontaine [21] suggest a simple model of revenue- or profit-sharing arrangements based on double-sided moral hazard and prove that the proposed model can account for many stylized facts. The contracts are helpful to align the pecuniary incentives of supply chain partners and induce successful forecast sharing. However, collaboration by contract is strongly influenced by the supply chain structure and is often difficult to apply in practice [15]. Meanwhile, we also find that the extant literature assumes that the supply chain members either absolutely trust, or do not trust the received information in decision making. Contrary to this all-or-nothing view, there is a continuum exists between these two extremes in industrial practices with EDI systems [7]. Since the industrial practice shows that EDI systems enable credible information sharing by soft-orders without complex contracts, we are primarily interested in how cooperation can arise and be effective in EDI systems under the circumstance of information symmetry and moral hazard. Actually, Özer et al. [7] determine the role of a non-pecuniary factor, trust, in cooperation via EDI and take the first step to incorporate trust in the economic modeling of contracts. We contribute to this literature by suggesting a trust evaluation model and mathematically formulates the supply chain decision-making process in EDI systems. Based on the characteristic of information sharing process with trust in EDI applications and the risk of lost sale, we suggest a trust-embedded contract to improve the supply chain performance and provide 'win-win' sustainable trades.

Actually, sharing information by soft-orders via EDI systems is pervasively used across industries [22], such as electronics [23] and semiconductors [24], medical equipment and commercial aircraft ([25], and so on. The suppliers consider their production (and material purchase) decisions referring to the received information of soft-orders through EDI systems. Theoretically, if the incentives of the information sender and supplier are too far apart, the soft-orders lead to uninformative communication [26]. The reliance on soft-orders is often deemed as trust and the supplier is assumed to filter information of demand based on his/her trust on soft-orders. Some industrial practice indicates that trust plays an essential role in supply chain operations [27]. There is a body of literature that investigates, from an evolutionary perspective, trust and its impact on information sharing with soft-orders. For example, Rouibah et al. [28] show that trust is helpful to each party in catching more information in interpersonal interactions. Moody et al. [29] believe trustworthiness is usually updated in transactions and insist on that a trustee's integrity has the strongest effect on perceived trustworthiness of a trustor. Doney and Cannon [30] have the similar viewpoint that a buyer's past successful experience of trust is helpful to future interactions with the seller. Ultimatum-bargaining experiments prove that trust goes along with trustworthiness, and the trust relationship is impaired by early-stage deceptions. Until recently, the role of trust playing in supply chain information sharing and decision-making has been studied. For example, Özer et al. [7] show the importance of trust in forecast information sharing and how trust affects related operational decisions. Afterwards, Ebrahim-Khanjari et al. [31] and Fu et al. [32] explore decisions of a three-tier supply chain with a multi-period trust updating model. Han and Dong [9] study a two-tier supply chain with one supplier and one retailer, each of which has negotiation power. Due to low performance of the supply chain, they explore the conditions of effective supply chain coordination considering negotiation powers of each party. Contrary to the extant literature, we focus on a retailer dominated two-tier supply chain where information is shared with soft-orders, and aim to mitigate the retailer's risk of lost sale. In this study, we formulate decision making process and suggest the retailer a contract based on a proposed trust evaluation model, which is built from the perspective of psychology.

A stream of literature studies the evaluation of trust. Since good reputation usually means a high level of trustworthiness [33], trustor's trust level can be evaluated by trustees' reputations [11]. Özer et al. [7] and Ebrahim-Khanjari et al. [34] assume trust as a predetermined parameter and contribute to identify how trust affects related operational decisions in various supply chain 
environments. Meanwhile, trust, as a type of psychological state, is also affected by decision makers' instant intuitions [34]. In other words, the feeling of trust is affected by both trustee's predetermined reputation and trustor's instant intuitions. With the help of modern psychometrical scales, trust level is able to be evaluated [35]. Based on some psychological researches, we suggest a trust evaluation model consisting of both predetermined parameter and instant parameter in this study. Particularly, we evaluate the trust level of a supplier who evaluates the market demand through two channels: historical demand and the retailer's ordered quantity. When the demand information from these two channels does not match, the supplier's trust decreases as a result of his trust-negative intuition, which is alternately presented as intuition gap in this paper. Obviously, higher information mismatch leads to lower trust level [36]. Similar to many extant literatures (e.g., [7,31], etc.), we consider the value of trust ranges in $[0,1]$. If the supplier fully trusts the reported demand, his trust level can be specified by a constant value 1 ; otherwise, the trust level is 0 if the supplier is fully distrusting. We prove in this study that EDI systems without a coordination mechanism leads to uncreditable information sharing, which potentially harms supply chain performance. In order to enhance the credibility of the information sharing, we suggest a regulate mechanism by a trust-embedded contract to provide sustainable 'win-win' cooperation.

It is often that retailers (sellers) dominate supply chains in industries, e.g., Wal-Mart and Carrefour in the retailing industry; McDonald's and KFC in the food industry; Apple Inc. and Nike in manufacturing industry, etc. Motivated by these industrial practices, we assume that the retailer dominates the two-tier supply chain with one supplier and one retailer. Both the supplier and the retailer have accesses to historical demand data, but the retailer has a private forecast of current market demand. Among the whole supply chain, the retailer is the closest to the market. With the help of IT, we could assume the retailer can accurately predict the distribution of demand. This is a reasonable assumption when the retailer has access to a substantial amount of historical data and forecasting data of the products [37]. Similar conclusions are also provided by both Fisher and Raman [38] and Schleifer and Bean [39]. In this paper, we are mostly interested in a retailer's ordering strategy for a sustainable cooperation when she trades with a partially trusting supplier. The main contributions of the paper are summarised as follows: (1) A trust evaluation model is formulated. Although reputation is deemed as an important factor in evaluating trustworthiness, we propose a trust evaluation model considering both the retailer's reputation and the supplier's intuition. (2) Because of the retailer's risk of lost sales and business fails because of incredible information sharing, we suggest a supply chain regulation mechanism by trust-embedded cost-sharing contract, which enhances the sustainability the supply chain trade in long run.

\section{Decisions in Decentralized Pattern}

\subsection{Modelling Trust}

Market demand is not known until the end of selling season, we thereby assume demand as a random variable following a fixed distribution. In particular, both the retailer and supplier's learning demand can be given by $D=\mu+\varepsilon$ [37], where $\mu$ is a positive constant denoting the average market demand and $\varepsilon$ describes the market uncertainty. Based on the historical data, both parties know that $\varepsilon$ is a zero-mean random variable with a cumulative distribution function (c.d.f.) $\Gamma(\varepsilon)$ and a probability density function (p.d.f.) $\tau(\varepsilon)$. The historical average demand is $\mu_{0}$, which is also public information and available to both parties. When the retailer-ordered quantity is $\mu_{R S}$, we allow $\frac{\left|\mu_{R S}-\mu_{0}\right|}{\mu_{0}}$ to represent the supplier's intuition gap. Main notations are presented in Table 1.

In addition, exponential distribution is one of the most significant distributions in statistical practice [40] and is widely used in psychology evaluation [41,42]. Many studies insist on that trust is a kind of psychological state and believe that trust follows an exponential distribution $[43,44]$. Since trust is affected by both trustee's reputation and trustor's intuition, we formulate trust as a variable affected by the two factors following an exponential distribution. 


$$
T=T_{0} \alpha^{\frac{\left|\mu_{R S}-\mu_{0}\right|}{\mu_{0}}}
$$

In Equation (1), $T_{0}$ is the supplier's trust based on the retailer's reputation. Thus, $T_{0}$ is able to deemed as initial trust and ranged in $[0,1]$. Because the supplier's trust will be harmed as long as the retailer's soft-order $\mu_{R S}$ is apart from the supplier's initial belief of demand $\mu_{0}$, we have $T_{0} \leq T$. Therefore, the supplier's intuition-sensitiveness of his own trust $\alpha$ is functioned in $(0,1)$. Because of $\alpha \in(0,1)$, we have $T$ decreases with $\frac{\left|\mu_{R S}-\mu_{0}\right|}{\mu_{0}}$, which highlights that high information mismatch leads to low trust levels [36]. If the retailer ordered quantity exactly equals to the historical average demand $\mu_{0}$, we say that the intuition gap is zero, and the supplier's trust level equals to his initial trust. Example 1 illustrates how the supplier's trust is affected by the intuition gap.

Table 1. Notations.

\begin{tabular}{lll}
\hline & $p_{S}$ & Supplier's wholesale price \\
& $p_{R}$ & Retailer's retail price \\
& $c$ & Production cost per product \\
& $c_{k}$ & Material cost for per product \\
Public information & $\mu_{0}$ & Historical average demand \\
& $\varepsilon$ & Market demand fluctuation \\
& $T_{0}$ & Intuition-sensitiveness coefficient \\
& $\mu_{R}$ & Reputation-induced trust \\
\hline Private information & $Q$ & Retailer-forecasted average demand \\
\hline \multirow{3}{*}{ Decision variable } & $m$ & Supplier planned output quantity \\
& $\mu_{R S}$ & Shared cost for per ordered product \\
& &
\end{tabular}

Example 1. The supplier's trust $T$, varies with $\mu_{R S}$ under the different intuition-sensitive coefficient $\alpha$ (see Figure 1).

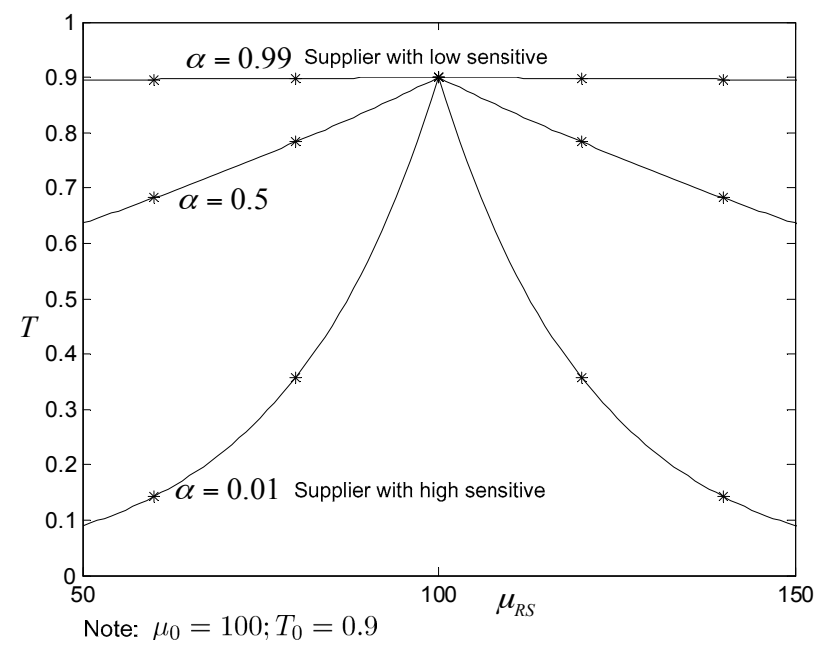

Figure 1. The supplier's trust on the retailer's reported demand.

Figure 1 shows that a highly sensitive supplier's trust is dramatically influenced by his intuition gap, but the result is the opposite for a less sensitive supplier. For example, for an extremely sensitive supplier $(\alpha \rightarrow 0)$, a small intuition gap leads to the supplier's large trust loss. An extremely less sensitive supplier $(\alpha \rightarrow 1)$ evaluates the trustworthiness of the retailer's order based primarily on her reputation. 


\subsection{Decisions in Decentralised Pattern}

After forecasting the market demand, the retailer places a soft-order $\mu_{R S}$ to the supplier, where the soft-order is cancellable at any time. The supplier updates his trust on the retailer's order based on the historical demand $\mu_{0}$ and the order $\mu_{R S}$ by Equation (1). Next, he decides his material quantity $Q$, which is able to produce exactly $Q$ quantity of product. As suggested by Clemen and Winkler [45], the supplier evaluates the market avarge demand by combining $\mu_{R S}$ and $\mu_{0}$ into a simple weighted average. Therefore, the supplier's belief of the average market demand is

$$
\mu_{S}=T \mu_{R S}+(1-T) \mu_{0}, \text { where } T=T_{0} \alpha^{\frac{\left|\mu_{R S}-\mu_{0}\right|}{\mu_{0}}}
$$

Because of $T \in(0,1)$, Equation (2) indicates that the average demand $\mu_{S}$ is a value between the retailer's ordered quantity $\mu_{R S}$ and the historical average demand $\mu_{0}$. According to Equation (2), we have $\lim _{\mu_{R S} \rightarrow \infty} \mu_{S}=\mu_{0}$ since $\alpha \in(0,1)$.

Without loss of generality, we assume that the wholesaling and retailing prices (i.e., $p_{S}$ and $p_{R}$ ) are predetermined. This paper is motivated by supply chain information sharing with EDI-type communications. In the transactions between supply chain partners, the downstream retailer makes private forecasting and places soft-orders via EDI systems. After receiving the retailer's soft-order, which is costless and cancellable before selling season, the supplier prepares production materials and undertakes the material cost. When selling season begins, the retailer places her final orders and makes payments. After that, the supplier makes fully use of production materials to produce products based on the retailer's orders, where the unsatisfied orders are disabled.

Because EDI systems aim to provide quick and less costly information sharing applications following the above process [46], this paper focuses on providing a trust evaluation model and proposing a coordination mechanism by contract. The profits of the retailer and supplier are formulated by Equations (3) and (4).

$$
\begin{gathered}
\Pi_{R}=\underset{\varepsilon}{E}\left[\left(p_{R}-p_{S}\right) \min \left(Q, \mu_{S}+\varepsilon\right)\right] \\
\Pi_{S}=\underset{\varepsilon}{E}\left[\left(p_{S}-c\right) \min \left(Q, \mu_{S}+\varepsilon\right)-c_{k} Q\right]
\end{gathered}
$$

where $\mu_{S}=T \mu_{R S}+(1-T) \mu_{0}$ and $T=T_{0} \alpha^{\frac{\left|\mu_{R S}-\mu_{0}\right|}{\mu_{0}}}$.

In Equations (3) and (4), $c$ and $c_{k}$ denote the production cost and material cost to produce one product, respectively. Since $Q$ denotes material quantity and the market demand is $\mu_{R}+\varepsilon$, the retailer's expected profit can be written as Equation (3). Moreover, the supplier's belief on market demand is $\mu_{S}+\varepsilon$, thus, its revenue can be presented by $\left(p_{S}-c\right) \min \left(Q, \mu_{S}+\varepsilon\right)$. Because the supplier pays $c_{k} Q$ for production materials, the supplier's expected profit can be formulated as Equation (4). Because the retailer decides the ordered quantity and the supplier determines his material quantity sequentially, their optimal decisions $\mu_{R S}^{*}$ and $Q^{*}$ can be calculated by Equations (3) and (4) by a standard Steinberg game.

Theorem 1. For $\forall \mu_{R}$, we have $\mu_{R S}^{*}=\mu_{0}\left(1-\frac{1}{\operatorname{Ln} \alpha}\right), Q^{*}=\Gamma^{-1}\left(\frac{p_{S}-c-c_{k}}{p_{S}-c}\right)+\mu_{0}-\frac{\mu_{0} T_{0}}{e \operatorname{Ln} \alpha}$.

Proof. See Appendix A.

Because intuition-sensitiveness coefficient $\alpha$, and historical demand $\mu_{0}$ are known by both the supplier and the retailer, the equilibrium solutions of the supply chain are demonstrated by Theorem 1 . Obviously, the retailer's retailing price is larger than supplier's wholesaling price, i.e., $p_{R}>p_{S}$. Because of the supplier's benefits from product selling, we have $p_{S}>c+c_{k}$. Thus, the predetermined variables in the solutions of $\mu_{R S}^{*}$ and $Q^{*}$ follow the constraints of $p_{R}>p_{S}>c+c_{k}, c>0$ and $c_{k}>0$.

The retailer is close to market and has advantages on obtaining demand information, e.g., consumer's buying habits, price elasticity, ethnic makeup, characteristic of substitute products, location 
of retailing branches, advertisement resources, etc. Meanwhile, modern sophisticated data-mining tools are helpful to analyse information from various aspects of market and forms demand forecast [47]. For example, Walmart is successful on demand forecast and EDI applications. Due to efficient and seamless integration of co-operators, Walmart employs Retail Link Database System to collect real time data. Based on the database, analysts of Walmart access the database and synchronize their demand forecast. Intuitively, demand forecast indicate the market states and is supposed to be considered in firms' operations. However, Theorem 1 shows that retailer's decision of soft-order $\mu_{R S}^{*}$ and supplier's decision of material quantity $Q^{*}$ are both independent on the retailer's forecast.

The finding of independence between supply chain decisions and retailer's forecast is interesting and analytically explanatory. As concluded by Lee et al. [23], demand information distortion in supply chain is due to double marginalization effect. For a given supply chain framework, how much demand information is distorted depends on the information sharing mechanism and participants' incentives [48]. In this paper, the efficiency of information sharing of the target problem is directly relevant to the information sharing mechanism of EDI systems. Specially, the supplier relies on both historical demand and soft-orders by a weight value of trust to evaluate market demand (Equation (2)), while the supplier's trust consists of his intuition which results from the difference between historical demand and retailer's soft-order (Equation (1)). To ensure abundant supply, the retailer strategically determines her ordered quantity by maximizing the supplier's evaluated quantity of demand, in which the retailer's private forecast is not included. Ineffective information sharing often means that the product supplier is not able to catch up with the real market fluctuation and leads to business failure to both supply chain partners [49]. For example, world-famous network-equipment provider Cisco had to write off $\$ 2.25$ billion inventory in 2001 because of failure market information sharing. According to a report by Baymard Institute, $68.55 \%$ online shopping carts are abandoned in UK in 2014 and one non-negligible reason of cart abandonment is untimely supply by online retailers [50]. This explains the reason why suppliers' tendency of searching for more information sources and retailers' risks of lost sales in limited-period EDI applications [51]. Because of a lack of feedback and punishment mechanisms in single-period transaction with EDI system, most EDI applications are more easily successful in multi-period transactions [52]. In this study, we focus on understanding the information sharing and decision making processes based on a trust model. Afterwards, due to the retailer's potential profit loss resulting from trust-based information sharing mechanism of EDI systems, we suggest the retailer a contract to strategically place orders according to her private forecast.

Remarks 1. Contrary to the finding in single-period transaction with EDI systems, the retailer's forecast directly affects supply chain decisions in multi-period transactions. In multi-period transactions, the retailer's initial trust $T_{0}^{t+1}$ period $t+1$ is updated by comparing the difference between realized demand $\mu^{t}$ and retailer's ordered quantity $\mu_{R S}^{t}$ in period t. Therefore, initial trust $T_{0}^{t+1}$ in period $t+1$ is a function of $\mu^{t}$ and $\mu_{R S}^{t}$ and is able to be calculated by a trust updating model $T_{0}^{t+1}=g\left(T_{0}^{t}, \mu^{t}, \mu_{R S}^{t}\right)$. Since real demand $\mu^{t}$ is not realized and known by the retailer when she decides her order (or the retailer preciously forecasts the market demand), she deems $\mu^{t}$ as her forecasted quantity of demand $\mu_{R}^{t}$. Therefore, retailer's forecast has influence on her evaluation of her initial trust, and therefore affects her decisions in current and forthcoming periods of transactions. In this study, we take the first step to provide a reasonable trust evaluation model and further present a solution to retailer's risk of lost sale based on the provided model. Future extending work is worthwhile to formulate trust updating process and study how forecast affects supply chain decisions in multi-period transactions.

We introduce $\mu_{R S}^{*}$ into Equation (1) and have the supplier's trust $T^{*}=\frac{T_{0}}{e} . T^{*}=\frac{T_{0}}{e}<T_{0}$ indicates that the retailer loses trust when she maximises her profit. Since the supplier's trust is directly affected by two factors, his intuition and the retailer's trustworthiness, Example 2 is employed to illustrate how they impact the supplier and retailer's profits.

Example 2. The supply chain decisions of $\mu_{R S}^{*}$ and $Q^{*}$ are independent on market forecast $\mu_{R}$ (Theorem 1 ), we visually present the retailer's potential loss with different value of $\mu_{R}$ by Figure 2. According to Theorem 1 , 
we can calculate the retailer's expected profit $\Pi_{R}^{*}$. Let $\Pi_{0 R}^{*}$ be the retailer's expected profit when demand forecast is incredibly shared, we find from Figure 2 that $\Pi_{R}^{*}>\Pi_{0 R}^{*}$ when $\mu_{R}<155$ and $\Pi_{R}^{*} \leq \Pi_{0 R}^{*}$ when $\mu_{R} \geq 155$. This observation highlights that there exists a threshold that the retailer benefits or suffers from the ineffective forecast sharing in single-period EDI applications. Since the retailer is able to benefit from EDI system when market demand is less than the threshold, she can pre-access her expected profit with the help of her forecast before placing soft-orders in EDI systems. To avoid lost sale, the retailer is motivated to strategically places soft-orders when her forecasted demand value is bigger than the threshold. This is the reason why we suggest the retailer a solution to mitigate the risk of lost sale by a contract in Section 4.

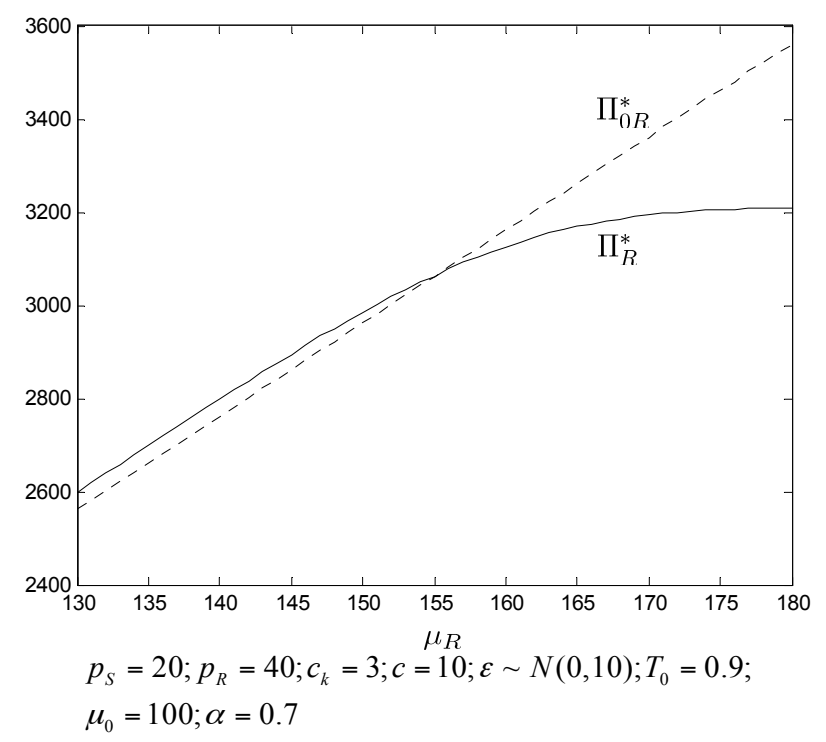

Figure 2. Retailer's expected profit under difference $\mu_{R}$.

When the supplier's trust-intuition parameter $\alpha$ is given and fixed, the effects of the retailer's initial trust is illustrated by Figure 3a. Because of Theorem 1, the retailer's optimal ordered quantity $\mu_{R S}^{*}$ is independent on her initial trust $T_{0}$, while the supplier's optimal material quantity $Q^{*}$ increases by $T_{0}$ (Figure 3a). Since the higher initial trust $T_{0}$ leads to a larger material quantity, the retailer's expected profit $\Pi_{R}^{*}$ increase by $T_{0}$ (Figure $3 b$ ). It highlights that the retailer's initial trust which results from good historical transaction record profits herself in the next transaction.
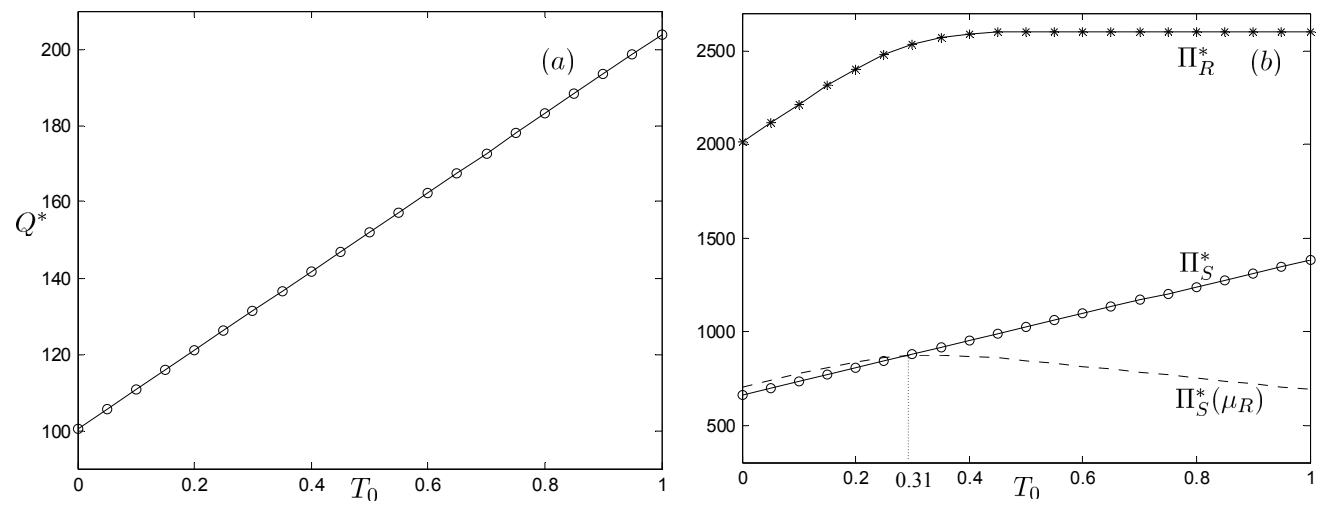

Note: $p_{S}=20 ; p_{R}=40 ; c_{k}=3 ; c=10 ; \varepsilon \sim N(0,10) ; \mu_{0}=100 ; \mu_{R}=130 ; \alpha=0.7$

Figure 3. The effects of the retailer's initial trust.

The supplier trusts more on a retailer who has high trustworthiness $T_{0}$ (Equation (2)), he thereby evaluates the demand is larger and prepare producing more products. Such that, the supplier's 
expected profit $\Pi_{S}^{*}$ increases by $T_{0}$. However, the supplier relies more on the order from a retailer who has high initial trust. When the supplier's evaluated demand $\mu_{S}$ is close to the real market demand $\mu_{R}$, the supplier's real profit $\Pi_{S}^{*}\left(\mu_{R}\right)$ is maximised. On contrary, the supplier's real profit $\Pi_{S}^{*}\left(\mu_{R}\right)$ is decreased if $\mu_{S}$ departs from $\mu_{R}$ (Figure 3a). In the experiment, we have $\Pi_{S}^{*}\left(\mu_{R}\right)>\Pi_{S}^{*}$ for $T_{0}<0.31$ and $\Pi_{S}^{*}\left(\mu_{R}\right)>\Pi_{S}^{*}$ for $T_{0}>0.31$. Therefore, the supplier faces potential loss when $T_{0}>0.31$ (Figure 3b).

According to Theorem 1 , both $\mu_{R S}^{*}$ and $Q^{*}$ increase by $\alpha$, which indicates that the retailer places a larger order if she deals with a less intuition-sensitive supplier (Figure 4a). It is easy understanding that a retailer will over-order if the supplier highly trusts her. Therefore, the retailer's expected profit increases by $\alpha$ (Figure 4a). Since the supplier's evaluated demand and planned material quantity also increases by $\alpha$, his expected profit $\Pi_{R}^{*}$ also increases by $\alpha$ (Figure $4 \mathrm{~b}$ ). Since the retailer orders more and a less intuition-sensitive supplier tends to produce more when $\alpha$ increases, the supplier's real expected profit decreases by $\alpha$. Therefore, a less intuition-sensitive supplier faces significant potential loss.
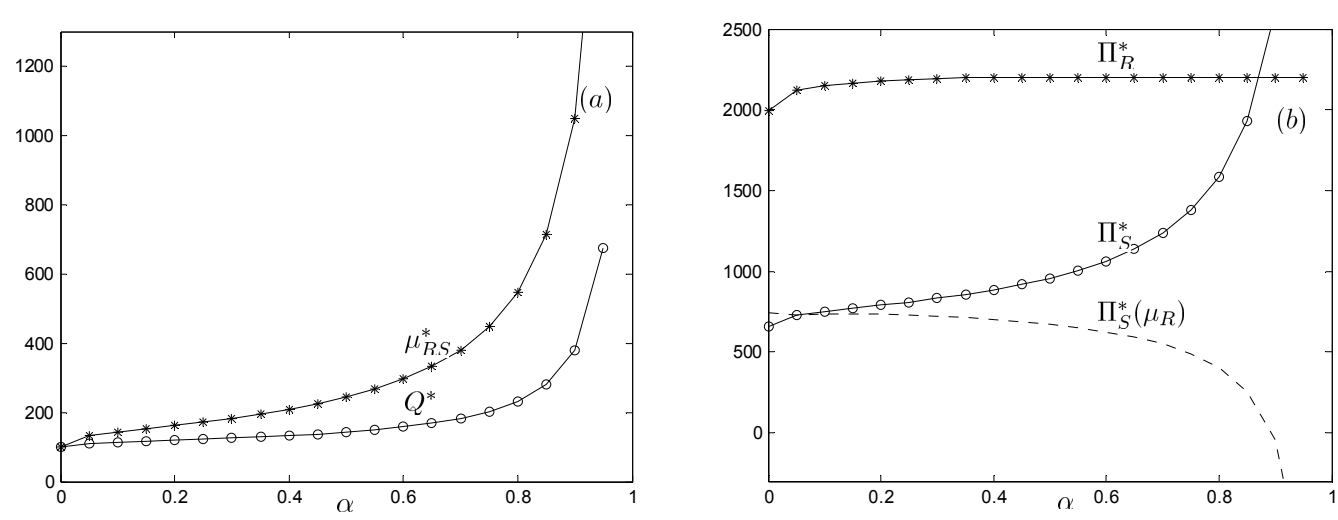

Note: $p_{S}=20 ; p_{R}=40 ; c_{k}=3 ; c=10 ; \varepsilon \sim N(0,10) ; T_{0}=0.8 ; \mu_{0}=100 ; \mu_{R}=130$

Figure 4. The effects of the supplier's intuition.

Traditional reputation-based trust evaluation model indicates $T=T_{0}$, thus, we introduce $T=T_{0}$ into Equations (3) and (4) and have the corresponding equilibrium solutions (see Corollary 1).

Corollary 1. The equilibrium solutions with $T=T_{0}$ are $\left.\mu_{S}^{*}\right|_{T=T_{0}}=\mu_{0}$ and $\left.Q^{*}\right|_{T=T_{0}}=\mu_{0}+\Gamma^{-1}\left(\frac{p_{S}-c-c_{k}}{p_{S}-c}\right)$.

Proof. See Appendix A.

If a supplier employs the traditional reputation-based trust evaluation model to filter the information from the retailer, Corollary 1 gives the corresponding equilibrium solutions. From Corollary 1 , we find that the supplier abandons any reported information from retailer and only relies on the historical demand $\mu_{0}$ in decision-making. The difference between $\left.\mu_{S}^{*}\right|_{T=T_{0}}=\mu_{0}$ and $\mu_{S}^{*}$ can be denoted by $\Delta$ :

$$
\Delta=\frac{\left.\mu_{S}^{*}\right|_{T=T_{0}}-\mu_{S}^{*}}{\mu_{S}^{*}}=\frac{1}{1-\operatorname{Ln} \alpha}
$$

Because of $\alpha \in(0,1)$, we have $\Delta \in[0,1]$ and find $\Delta$ increases by $\alpha$. Comparing with the proposed mixed reputation-intuition based trust model, a proportion of $\Delta$ information is failed to deliver under the traditional reputation-based trust model. Thus, the traditional reputation-based trust model is less efficient in information sharing.

Equation (3) indicates that $\Pi_{R}$ increases with $Q$. Because of $\left.Q^{*}\right|_{T=T_{0}}<Q^{*}$, we have $\Pi_{R}\left(\left.Q^{*}\right|_{T=T_{0}}\right)<\Pi_{R}\left(Q^{*}\right)$. Compared to the expected profit of reputation-intuition trust model, the retailer's expected profit of reputation-based trust model is much lower. From Equation (4), we also find that $\Pi_{S}$ increases with both $Q$ and $\mu_{S}$. Since $\left.\mu_{S}^{*}\right|_{T=T_{0}}<\mu_{S}^{*}$ and $\left.Q^{*}\right|_{T=T_{0}}<Q^{*}$, we have 
$\Pi_{S}\left(\left.\mu_{S}^{*}\right|_{T=T_{0}},\left.Q^{*}\right|_{T=T_{0}}\right)<\Pi_{S}\left(\mu_{S}^{*}, Q^{*}\right)$. In summary, both the retailer's and the supplier's expected profits from reputation-based trust model are smaller than those from reputation-intuition based trust model.

\section{Trust-Embedded Binding Contract for Sustainable Trade}

Credible information sharing in the information asymmetry situation is extremely hard due to the double marginalization effects in supply chain. Theorem 1 shows that the supplier's optimal decision is independent of the real market demand; information sharing fails and harms both partners of the supply chain. For example, when the market demand is significantly larger than the historical demand, both the retailer and supplier suffers from great potential loss of selling opportunity. Thus, both of them are motived to cooperate under a coordination mechanism.

Meanwhile, trust has its values and plays an important role in business. For example, when Volkswagen, a world-famous car producer, was reported of cheating on engines' emission rating, their trustworthiness decreases badly in a very short time and their shares value dropped nearly $20 \%$ within a day. Therefore, trust affects decision makers' behaviors (Table 2) and is often considered in business cooperation agreement. In Uber's practice, high-rating driver is more trustful by passengers, which indicates better passenger experience and helps Uber to earn more business opportunities. Thus, Uber punishes the consistently low-rating drive-partners by deactivating their account and reward the top-rated ones following the driver-reward program [53].

Table 2. The Effluence of Trust to Behaviors [54].

\begin{tabular}{ccc}
\hline State of Trust & Motivation Force & Behavior \\
\hline Highly invested & For the good the whole & Responsible \\
Transaction oriented & For successful project & Willing \\
Reluctant or cautious & To look good & Shrewd \\
Distrust & Not to lose & Cut-throat \\
\hline
\end{tabular}

Traditionally, many mechanisms (such as cost-sharing, buy-back, batch discounts, etc.) are adopted to coordinate the supply chain with asymmetric information, where the shared information is deemed to be totally distrustful. Since trust is the underlying reason of information sharing by EDI systems and affects supply chain partners' behaviors (Table 2), trust needs to be considered in the coordination mechanism by contract. Actually, trust is considered in contract in some EDI-based information sharing applications. For example, EDI system is employed to share demand and supply information between Walmart partners. The trustworthiness of suppliers is evaluated by a Supplier Evaluation Risk (SER) Rating process in Walmart-EDI system and low-trust suppliers are required to provide more insurance coverage in their cooperation contract [55]. The trust-embedded insurance plan in Walmart-EDI system decreases the risks of supply, and provide more sustainable cooperation between Walmart and its suppliers. Motivated by the practice of Walmart, we are primarily interested in suggesting a trust-embedded contract to coordinate the supply chain and increase the supply chain partner's expected profit under information asymmetry.

Since the supplier's production decision is independent to the market forecast (Theorem 1) that potentially harms both the retailer and supplier, a regulation mechanism by trust-embedded cost-sharing contract is proposed to coordinate the supply chain. The contract is performed in two stages. In the first stage, after forecasting the market demand $\mu_{R}$, the retailer places an order $\mu_{R S}$ with her supplier and provides a shared cost $m$ on per ordered product. In the second stage, the supplier updates his trust $T$ and evaluates demand $\mu_{S}$ based on the order and historical demand information. If the supplier accepts the shared cost, he will guarantee that the ordered quantity will be satisfied. We say the order is "bound". Otherwise, the supplier will not guarantee the order and the order is "unbound". For example, if a retailer places an order $\mu_{R S}=190$, the supplier's optimal prepared materials for products after updating his demand evaluation is $Q=50$. To encourage the supplier 
to prepare more materials, the retailer is motivated to share a cost $m$ for each ordered quantity. If the supplier accepts the shared cost $m$, he binds the order and produces at least 190 products. Otherwise, his does not bind the order and his optimal material quantity is 50 .

\subsection{The Retailer's Profit}

Let $m$ represent the shared cost of per ordered product. The retailer's profit in the contract is formulated as

$$
\widetilde{\Pi}_{R}=\underset{\varepsilon}{E}\left[\left(p_{R}-p_{S}\right) \min \left(Q, \mu_{S}+\varepsilon\right)\right]-m \mu_{R S}
$$

For mathematical convenience, we let $\widetilde{H}_{R}$ denote $\underset{\varepsilon}{E}\left[\left(p_{R}-p_{S}\right) \min \left(Q, \mu_{S}+\varepsilon\right)\right]$. In the decentralised pattern, the retailer's optimal order is $\mu_{R S}^{*}=\mu_{0}\left(1-\frac{1}{\operatorname{Ln\alpha }}\right)$ and the supplier's optimal material quantity is $Q^{*}=\Gamma^{-1}\left(\frac{p_{S}-c-c_{k}}{p_{S}-c}\right)+\mu_{0}-\frac{\mu_{0} T_{0}}{e L n \alpha}$ (Theorem 1$)$. Thus, the retailer's corresponding expected profit in the decentralised pattern is

$$
\Pi_{R}^{*}=\underset{\varepsilon}{E}\left[\left(p_{R}-p_{S}\right) \min \left(\Gamma^{-1}\left(\frac{p_{S}-c-c_{k}}{p_{S}-c}\right)+\mu_{0}-\frac{\mu_{0} T_{0}}{e \operatorname{Ln\alpha }}, \mu_{R}+\varepsilon\right)\right]
$$

The retailer is willing to share cost $m \mu_{R S}$ for binding her order only when her expected profit from binding is no less than that in the decentralised pattern, so we have $\widetilde{\Pi}_{R} \geq \Pi_{R}^{*}$.

\subsection{The Supplier's Profit}

Meanwhile, the supplier's profit in the contract is formulated as

$$
\widetilde{\Pi}_{S}=\underset{\varepsilon}{E}\left[\left(p_{S}-c\right) \min \left(Q, \mu_{S}+\varepsilon\right)-c_{k} Q+m \mu_{R S}\right]
$$

Similarly, we let $\widetilde{H}_{S}$ denote $\underset{\varepsilon}{E}\left[\left(p_{S}-c\right) \min \left(Q, \mu_{S}+\varepsilon\right)-c_{k} Q\right]$ for mathematical convenience. Note that for an ordered quantity $\mu_{R S}$, the supplier evaluates the demand as $\mu_{S}=T \mu_{R S}+(1-T) \mu_{0}$ (Equation (2)) and his optimal material quantity in the decentralised pattern (Equation (A5)) is $Q^{*}\left(\mu_{R S}\right)=T \mu_{R S}+(1-T) \mu_{0}+\Gamma^{-1}\left(\frac{p_{S}-c-c_{k}}{p_{S}-c}\right)$. Therefore, when the retailer orders $\mu_{R S}$, the supplier's optimal profit $\Pi_{S}^{*}\left(\mu_{R S}\right)$ is

$$
\begin{aligned}
\Pi_{S}^{*}\left(\mu_{R S}\right)= & \underset{\varepsilon}{E}\left[\left(p_{S}-c\right) \min \left(T \mu_{R S}+(1-T) \mu_{0}+\Gamma^{-1}\left(\frac{p_{S}-c-c_{k}}{p_{S}-c}\right), T \mu_{R S}+(1-T) \mu_{0}+\varepsilon\right)\right. \\
& \left.=-c_{k}\left(T \mu_{R S}+(1-T) \mu_{0}+\Gamma^{-1}\left(\frac{p_{S}-c-c_{k}}{p_{S}-c}\right)\right)\right]
\end{aligned}
$$

Note that the supplier accepts the retailer's request for binding only when his profit in binding is no less than that without binding. That is to say, the supplier guarantees $Q \geq \mu_{R S}$ only when $\widetilde{\Pi}_{S} \geq \Pi_{S}^{*}\left(\mu_{R S}\right)$.

\subsection{Objective Model}

According to Equations (5) and (8), the retailer and supplier's decision model is summarised as

$$
\begin{gathered}
\max _{\mu_{R}, m} \widetilde{\Pi}_{R} \\
\text { s.t. } \widetilde{\Pi}_{R} \geq \Pi_{R}^{*}
\end{gathered}
$$

$$
\begin{aligned}
& \max _{Q} \widetilde{\Pi}_{S} \\
& \text { s.t. } Q \geq \mu_{R S} \quad \text { if } \quad \widetilde{\Pi}_{S} \geq \Pi_{S}^{*}\left(\mu_{R S}\right)
\end{aligned}
$$

Because the retailer and supplier make decisions sequentially, we solve the supplier's decision primarily. Next, we introduce the supplier's reaction into Equation (9) and obtain the retailer's decision. Let $\widetilde{\mathrm{m}}^{*}, \widetilde{\mu}_{R S}^{*}, \widetilde{Q}^{*}$ denote the solution of Equations (9) and (10), such that we obtain Proposition 1. 
Proposition 1. For $\forall \mu_{R}$, we have $\left\{\widetilde{\mathrm{m}}^{*}, \widetilde{\mu}_{R S}^{*}, \widetilde{Q}^{*}\right\} \Uparrow \phi$.

Proof. See Appendix A.

Proposition 1 indicates that there exists an optima solution. Since the retailer's expected profits in the contract are no less than that in decentralised pattern, the retailer will choose the contract when she deals with a partially trusting supplier.

\subsection{Model Solutions}

As the follower in the decision processes, the supplier decides whether accepts the binding request and determines the quantity of prepared materials based on the retailer's decision on $\mu_{R S}$ and $m$. Meanwhile, the retailer's decisions are made according to her supplier's reactions. Therefore, a backward deduction is adopted to solve the objective model Equations (9) and (10) in a Steinberg game. The solution is presented by Proposition 2 .

Proposition 2. The solution of the objective model is

$$
\begin{gathered}
\widetilde{\mathrm{m}}^{*}=\left\{\begin{array}{l}
\frac{\Pi_{S}^{*}\left(Q^{*}\right)-\widetilde{H}_{S}\left(\mu_{R S}\right)}{\mu_{R S}} \text { if } \widetilde{H}_{R}\left(\mu_{R S}, \mu_{R S}\right)-\Pi_{R}^{*} \geq \Pi_{S}^{*}\left(Q^{*}\right)-\widetilde{H}_{S}\left(\mu_{R S}\right) \\
0 \text { otherwise }
\end{array}\right. \\
\widetilde{\mu}_{R S}^{*}= \begin{cases}\operatorname{argmax} \widetilde{\Pi}_{R S} & \text { if } \quad \widetilde{H}_{R}\left(\mu_{R S}, \mu_{R S}\right)-\Pi_{R}^{*} \geq \Pi_{S}^{*}\left(Q^{*}\right)-\widetilde{H}_{S}\left(\mu_{R S}\right) \\
\mu_{0}\left(1-\frac{1}{\operatorname{Ln\alpha })}\right. \text { otherwise }\end{cases} \\
\widetilde{Q}^{*}= \begin{cases}\mu_{R S} \text { if } \widetilde{H}_{R}\left(\mu_{R S}, \mu_{R S}\right)-\Pi_{R}^{*} \geq \Pi_{S}^{*}\left(Q^{*}\right)-\widetilde{H}_{S}\left(\mu_{R S}\right) \\
\Gamma^{-1}\left(\frac{p_{S}-c-c_{k}}{p_{S}-c}\right)+\mu_{0}-\frac{\mu_{0} T_{0}}{e L n \alpha} & \text { otherwise }\end{cases} \\
\text { Where, } Q^{*}=\Gamma^{-1}\left(\frac{p_{S}-c-c_{k}}{p_{S}-c}\right)+T_{0} \alpha^{\frac{\left|\mu_{R S}-\mu_{0}\right|}{\mu_{0}}} \mu_{0}-T_{0} \alpha^{\frac{\left|\mu_{R S}-\mu_{0}\right|}{\mu_{0}}} \mu_{R S}+\mu_{R S}
\end{gathered}
$$

Proof. See Appendix A.

The retailer and supplier's decisions can be obtained by Proposition 2. The condition $\widetilde{H}_{R}\left(\mu_{R S}, \mu_{R S}\right)-\Pi_{R}^{*} \geq \Pi_{S}^{*}\left(Q^{*}\right)-\widetilde{H}_{S}\left(\mu_{R S}\right)$ indicates that the retailer maximal offered shared cost is no less than the shared cost that the supplier tolerated on binding the soft-order. Therefore, the supply chain partners decide to bind the retailer's soft-order. Conversely, when $\widetilde{H}_{R}\left(\mu_{R S}, \mu_{R S}\right)-\Pi_{R}^{*}<$ $\Pi_{S}^{*}\left(Q^{*}\right)-\widetilde{H}_{S}\left(\mu_{R S}\right)$, the retailer decides to unbind the retailer's soft-order. Both the solutions under the two situations are given by Proposition 2. However, because the optimal solutions $\widetilde{\mathrm{m}}^{*}, \widetilde{\mu}_{R S}^{*}$ and $\widetilde{Q}^{*}$ are complex function of $\mu_{R S}$ and $\mu_{0}$, respectively, analytical study of the optimal solutions $\left\{\widetilde{\mathrm{m}}^{*}, \widetilde{\mu}_{R S}^{*}, \widetilde{Q}^{*}\right\}$ is prohibitively complicated. We provide a numerical study to gain some managerial insights.

\section{Numerical Study and Discussion}

To find the effect of trust on decisions and the performance of the proposed cost-sharing contract, we set up experiments as follows. The analytical problems include:

(1) The value of trust. In the contract, the retailer has opportunity to bind her soft-order for guaranteed supply. We find the maximum tolerated price that the retailer will share for the distrust, and the minimum price that the supplier will tolerate. The value of trust is quantified and analysed in experiments in which we determine whether the retailer and supplier value trust differently.

(2) The impact of reputation. We analyse how much the retailer benefits from her reputation and try to explain why reputation is so important in business. 
(3) The impact of intuition. The supplier's intuition directly influences his trust. Because different suppliers have different intuitions, we analyse the impact of the supplier's intuition on the retailer and supplier's profits.

(4) The efficiency of the proposed contract. The solution of the contract is given in Section 4. We analyse whether both the retailer and supplier benefit from the contract and whether the supply chain turns to be a 'win-win' sustainable pattern.

\subsection{The Value of Trust}

Because the supplier claims that shared costs ameliorate distrust-induced uncertainty, the retailer balances the shared cost $V_{R}$ and the increased profit that stems from increased trust when she makes decisions. The retailer benefits from the increased production ability by sharing some parts of material cost and has her order bounded only when $\widetilde{H}_{R}-m \mu_{R S} \geq \Pi_{R}^{*}$. Therefore, we obtain $m \mu_{R S} \leq \widetilde{H}_{R}-\Pi_{R}^{*}$, which indicates that the retailer spends as most as $V_{R}=\widetilde{H}_{R}-\Pi_{R}^{*}$ to bind her soft-order due to the supplier's distrust. Because of $\widetilde{H}_{S}+m \mu_{R S} \geq \Pi_{S}^{*}$, we have $m \mu_{R S} \geq \Pi_{S}^{*}-\widetilde{H}_{S}$. The supplier claims at least as $V_{S}=\Pi_{S}^{*}-\widetilde{H}_{S}$ material cost to bind the order. Compared with the retailer's initial trust, the retailer decreased trustworthiness is denoted by $\Delta T=T_{0}-T_{0} \alpha^{\frac{\left|\mu_{R S}-\mu_{0}\right|}{\mu_{0}}}$. Therefore, $V_{S}$ and $V_{R}$ are the supplier's minimum and the retailer's maximum tolerated shared cost for $\Delta T$.

Observation 1. (1) The retailer and supplier value trust differently; and (2) it takes many trust-positive efforts to get trusted more.

Given a certain value of $T_{0}$, we change the value of $\mu_{R S}$ and arrive at the value of $V_{R}, V_{S}$ and $\Delta T$ (Figure 5). We find that $V_{S}$ is a convex function of $\Delta T$ and increases with. In addition, we observe that $V_{R}$ is concave with $\Delta T$. The findings that $V_{S}(\Delta T \leq 0.15) \leq V_{R}(\Delta T \leq 0.15)$ and $V_{S}(\Delta T>0.15)>V_{R}(\Delta T>0.15)$ indicate that the retailer and the supplier evaluate the value of trust differently. Because the supplier charges at least $V_{S}$ and the retailer tolerates at most $V_{R}$ for binding her order, the acceptable shared cost by both the supplier and the retailer to cover distrust-induced shrink of material quantity is ranged in $S$ in Figure 5. Meanwhile, $\frac{d V_{S}}{d \Delta T}>0$ (Figure 5) indicates that it takes a great deal of trust-positive efforts (in this paper, "shared cost") to earn trust.

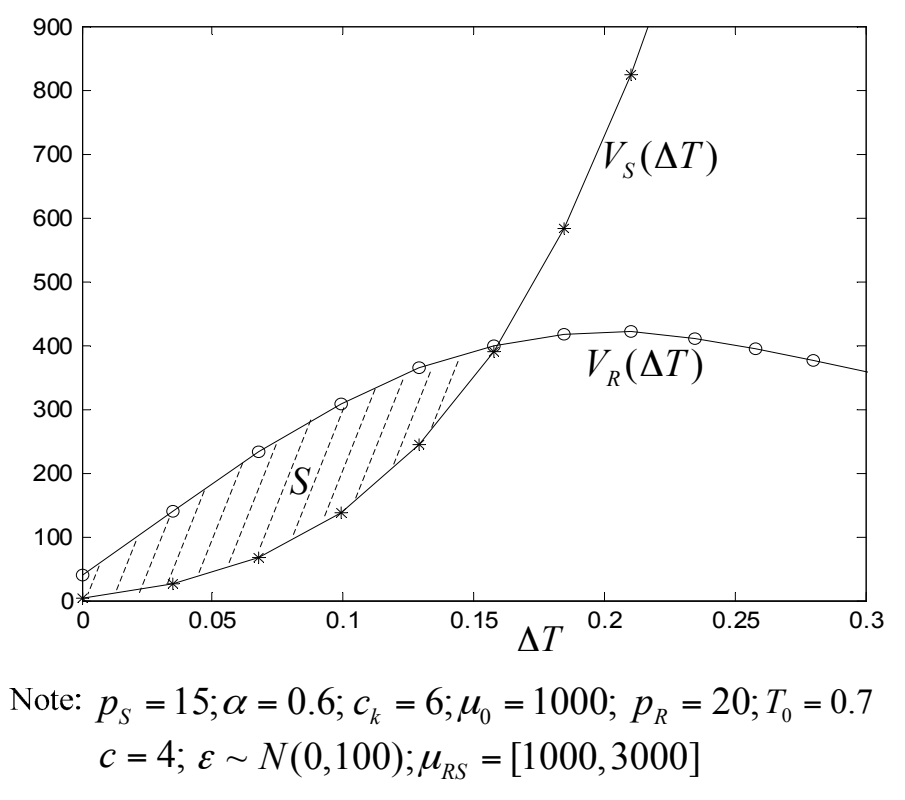

Figure 5. The trust price from the supplier and retailer's perspectives.

Maintaining customer trust costs great in competitive markets. For example, in 2012 Nike spent a total of $\$ 2.7$ billion on marketing (including marketing expenses, marketing support, investment in 
product presentation, etc.) to maintain its reputation and gain customers' trust. Because maintaining (and earning) customers' trust requires investment, decision makers do not necessarily seek the highest trustworthiness. Since it is observed that $V_{R}$ is concave with $\Delta T$, and $V_{S}$ is convex with $\Delta T, S$ is the cost that is acceptable both to the retailer and the supplier.

\subsection{The Impact of Reputation}

Since high reputation usually means high trustworthiness, firms try to keep a high reputation in transactions. The trust level because of the retailer's reputation is known as initial trust, we calculate the retailers' profit at different trust levels and arrive at Observation 2.

Observation 2. Retailers benefit from high reputation, especially in a situation in which the real market demand is high.

When we fix all of the parameters except for the initial trust $T_{0}$ in a transaction, we find that the expected profit of a retailer with high initial trust is larger than that of a retailer with lower initial trust. For example, we examine the effect of reputation in Figure 6. We notice that when $\mu_{R}=110$, the retailer's expected profit increases with its initial trust $T_{0}$. In other words, the retailer obtains more profit if her reputation is higher. When this experiment is repeated under different situations of $\mu_{R}=130$ and $\mu_{R}=150$, the observation still holds.

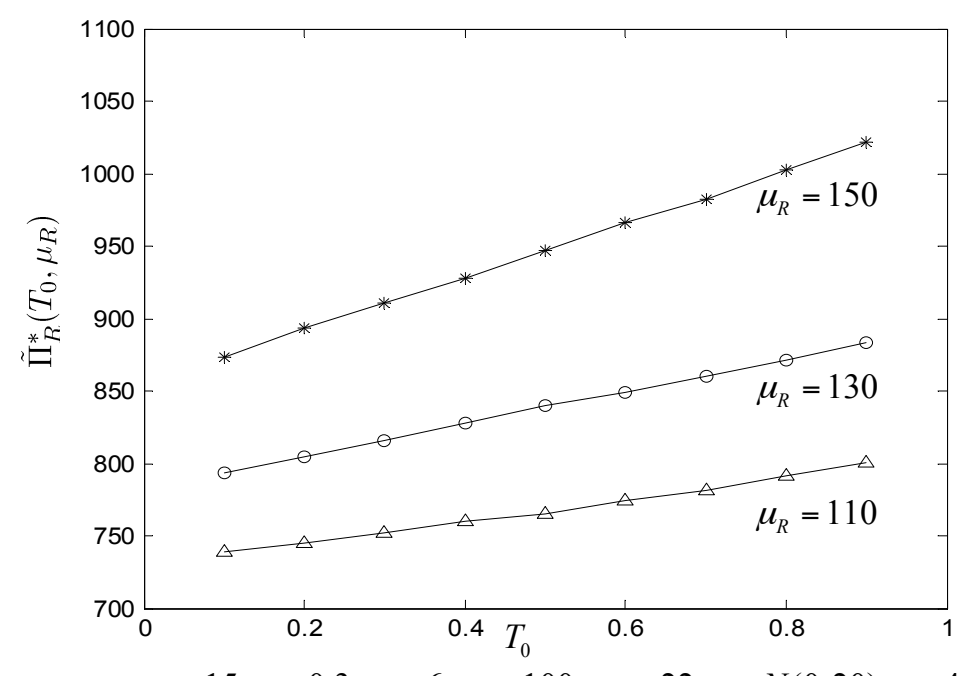

Note: $p_{S}=15 ; \alpha=0.3 ; c_{k}=6 ; \mu_{0}=100 ; p_{R}=22 ; \varepsilon \sim N(0,20) ; c=4$

Figure 6. Reputation-induced trust's effects on the retailer's profit.

We also compare the effectiveness of the retailer's reputation in different market situations. Allow $\widetilde{\Pi}_{R}^{*}\left(T_{0}, \mu_{R}\right)$ to represent the retailer's maximum profit and average market demand is $\mu_{R}$. We find in Figure 6 that $\frac{\partial \widetilde{\Pi}_{R}^{*}\left(T_{0}, 150\right)}{\partial T_{0}}=168.75 ; \frac{\partial \widetilde{\Pi}_{R}^{*}\left(T_{0}, 130\right)}{\partial T_{0}}=106.25$ and $\frac{\partial \widetilde{\Pi}_{R}^{*}\left(T_{0}, 110\right)}{\partial T_{0}}=73.75$. This indicates that the effectiveness of reputation for increasing the retailer's profit is increased along with the market demand $\mu_{R}$.

Observation 2 highlights the importance of reputation in transactions, which can be interpreted as that the reputation has positive effectiveness on information sharing and therefore helps decision makers to obtain more revenue, especially when the market demand is larger. This indicates that good reputation plays an even more important role in big business, this observation that matches real industrial practices, especially regarding online businesses [56]. For example, sellers with more than 675 positive comments earned a premium of $\$ 45.76$, more than $10 \%$ of the mean selling price, compared to new sellers with no comments on online transactions on eBay [57]. 


\subsection{The Impact of Intuition}

A more intuition-sensitive supplier tends to trust the retailer's ordered quantity less and mostly relies on historical demand to prepare his material. Because the retailer's profit is directly linked with the supplier's maximum potential production quantity which is linked to the quantity of the prepared materials, the intuition-sensitiveness coefficient affects both the retailer and supplier's decisions.

Observation 3. The retailer tends to bind her order when she trades with a highly intuition-sensitive supplier.

Figure 7 shows the retailer's profits when the supplier's intuition-sensitiveness equals different values. It shows that retailers obtain more expected profit when the supplier's intuition-sensitiveness is low. This observation is reasonable and follows practice experiences.

Note that high intuition-sensitiveness means that the supplier loses more trust for a certain intuition gap, and the retailer shares more portions of material costs to obtain a certain production ability in a cost-sharing contract. When $\alpha \leq 0.26$, the retailer binds her order and we have $\widetilde{\mu}_{R S}=\widetilde{Q}^{*}$. However, the retailer has her order unbound when $\alpha \geq 0.26$ because the expense on binding is larger than increased profit (Figure 8a). Because a less sensitiveness supplier relies more on the retailer's orders, a large order obviously leads to a larger material quantity and the retailer is less incentive to share material cost with the supplier.

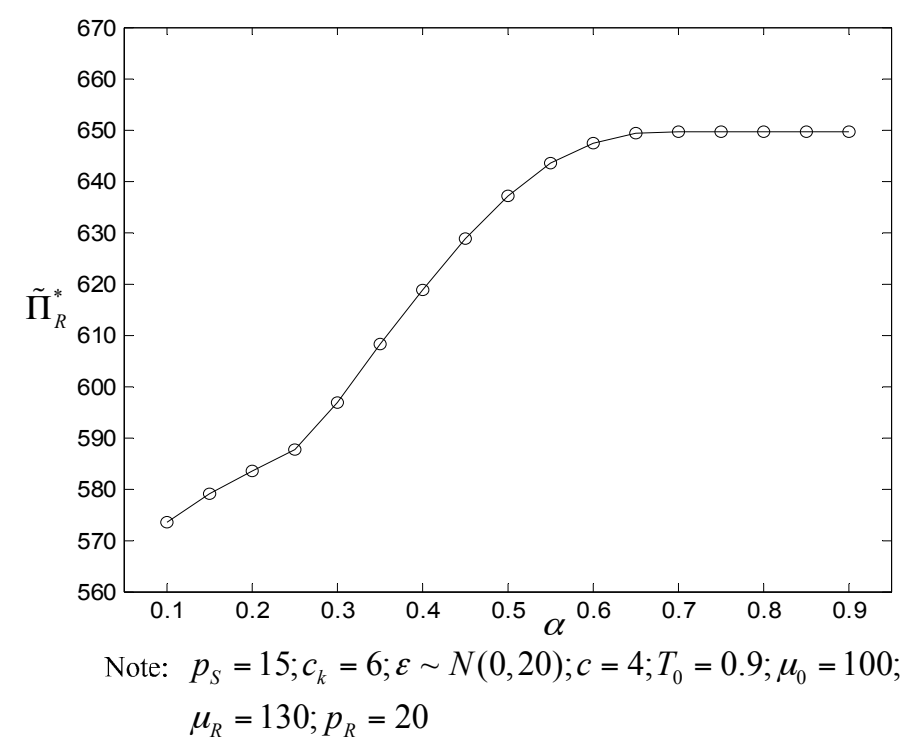

Figure 7. The retailer's profit under suppliers with different intuition-sensitiveness.
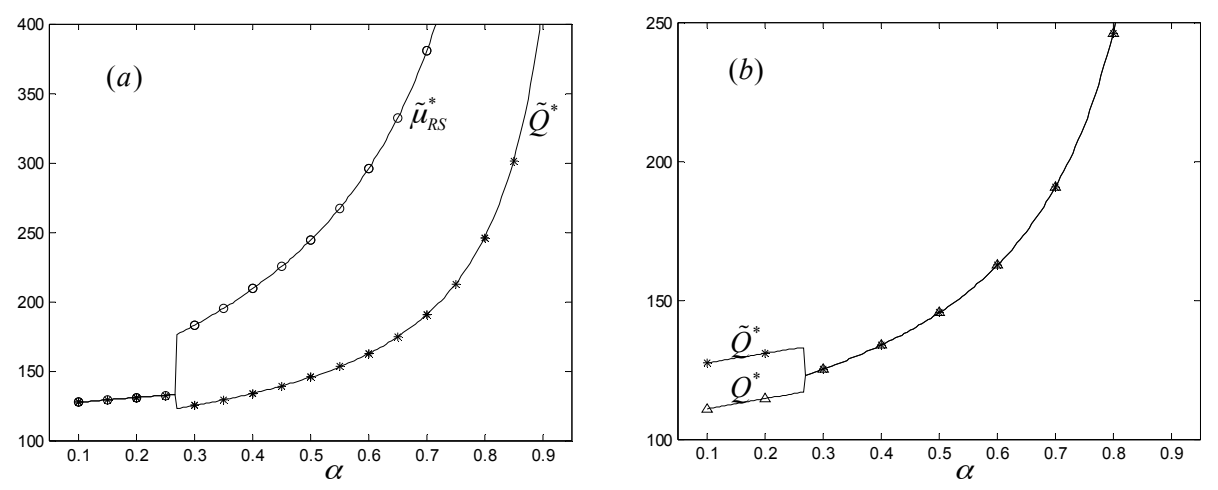

Note: $p_{S}=15 ; c_{k}=6 ; \varepsilon \sim N(0,20) ; c=4 ; T_{0}=0.9 ; \mu_{0}=100 ; \mu_{R}=130 ; p_{R}=20$

Figure 8. Order decisions and production quantities with different $\alpha$. (a). (b). 
This finding also highlights that the retailer's revenue margin from binding increases with the supplier's intuition-sensitiveness (Figure $8 \mathrm{~b}$ ). Therefore, when the retailer trades with a highly intuition-sensitive supplier, she tends to bind her order. However, if she deal with a less intuition-sensitive supplier, she tends to have her order unbound.

Observation 4. The supplier's real profit is positively affected by his trust intuition.

Equation (2) shows that the supplier updates his evaluation of the average market demand $\mu_{S}$ based on a retailer's order $\mu_{R S}$ and historical information $\mu_{0}$. Next, the supplier determines his material quantity $\widetilde{Q}^{*}$ based on his evaluation on demand. Since the retailer's optimal order $\widetilde{\mu}_{R S}^{*}$ is affected by the supplier's intuition coefficient $\alpha$, the supplier's decision $\widetilde{Q}^{*}$ is linked with $\alpha$ (Proposition 2). Therefore, the parameter $\alpha$ indirectly affects the supplier's expected profit $\widetilde{\Pi}_{S}^{*}$. However, the real market demand is $\mu_{R}$, the supplier may be mislead by the retailer's ordered information $\mu_{R S}$. Therefore, we examine influence of supplier's intuition $\alpha$ on suppliers' real $\widetilde{\Pi}_{S}^{\prime *}$ (Figure 9).

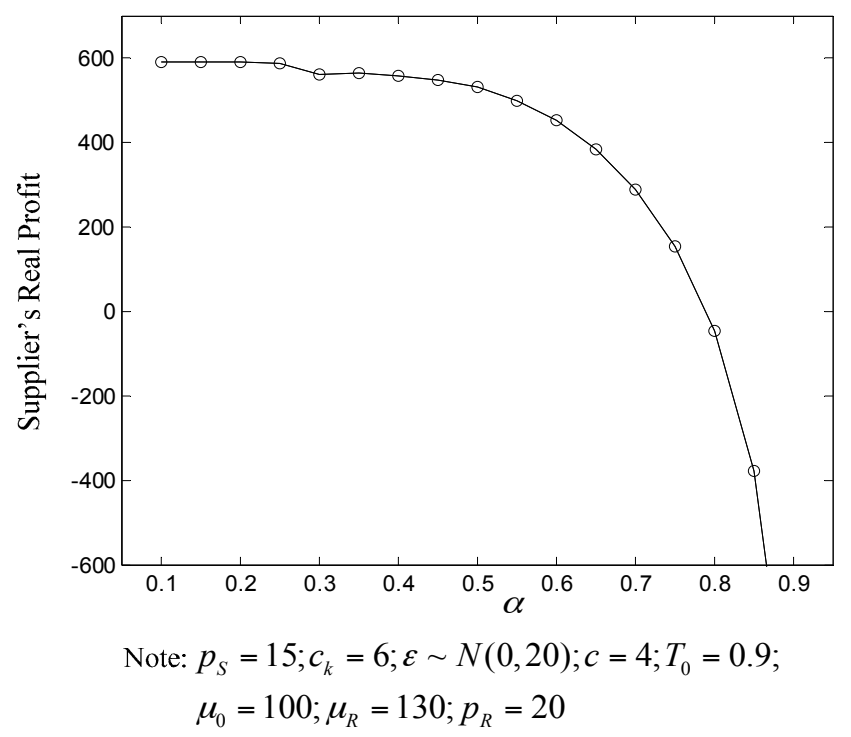

Figure 9. Influence of intuition on suppliers' profits.

Note the fact that the less intuition-sensitive supplier relies more on the retailer's order, and the retailer tends to over-order and has the order unbound when her supplier's intuition-sensitiveness is low. The less intuition supplier thereby over-evaluates the demand and his prepared production materials deviates much from the real market demand. Thus, the supplier's intuition helps him to gain more revenue from the retailer since he does not have access to the retailer's private information.

\subsection{Efficiency of the Regulation Mechanism by Contract}

The trust-embedded cost-sharing contract is proposed to help the retailer make flexible order decisions when she trades with partially trusting suppliers. Meanwhile, the supplier's potential loss stemming from order bind is hedged by the retailer's shared cost. Therefore, both the retailer and supplier benefit from a binding contract in the retailer-dominated supply chain. The contract performances are demonstrated by the following experiments.

Observation 5. Both the retailer and supplier benefit from the binding contract.

We conduct experiments with different values of real demand $\mu_{R}$ to examine the performance of the contract under different market demand situations.

In Figure 10a, $\widetilde{\Pi}_{R}^{*}$ and $\Pi_{R}^{*}$ are the retailer's expected profit in the contract and decentralised pattern, respectively. Compared with the profit in the decentralised pattern, the retailer earns more 
profit in the contract. This observation is understandable in that when average demand $\mu_{R}$ is bigger than 82 , which is less than the historical market demand $\alpha$, the retailer would rather unbinds her order and her maximum profit is the same with that in the decentralised pattern. However, when $\mu_{R}$ is more than 82 , the retailer choose to bind the order and her profit in the contract is larger than that in the decentralised pattern. We observe that the contract performs more effectively when market demand $\mu_{R}$ is large. Let $\frac{\widetilde{\Pi}_{R}^{*}}{\Pi_{R}^{*}}$ indicates the effectiveness of the contract with respect to the retailer's profits; we have $\frac{\widetilde{\Pi}_{R}^{*}}{\Pi_{R}^{*}}=105 \%$ when $\mu_{R}=\mu_{0}$, while $\frac{\widetilde{\Pi}_{R}^{*}}{\Pi_{R}^{*}}$ increases to $113 \%$ when $\mu_{R}=200$.

Note that the retailer dominates the supply chain and possesses demand information; it is understandable that she benefits from the flexible order strategy by the contract. Because the supplier's material preparation decision is made based on the retailer's order decision, we examine whether the supplier also benefits from the contract. The supplier believes that the market demand is $\mu_{S}$ and his expected profit is $\Pi_{\mathcal{S}}^{*}$. However, the real market average demand is $\mu_{R}$, and his real profit in the decentralised pattern is $\widetilde{\Pi}_{S}^{\prime *}$. Some percentages of the increased profit derive from the retailer's shared cost in the contract (Figure 10a). Figure 10b shows that the supplier's real profit in the contract $\widetilde{\Pi}_{S}^{\prime *}$ is larger than that in the decentralised pattern. Most importantly, the supplier catches up with real demand indirectly through the contract, while he makes decisions only based on historical information without the proposed contract.
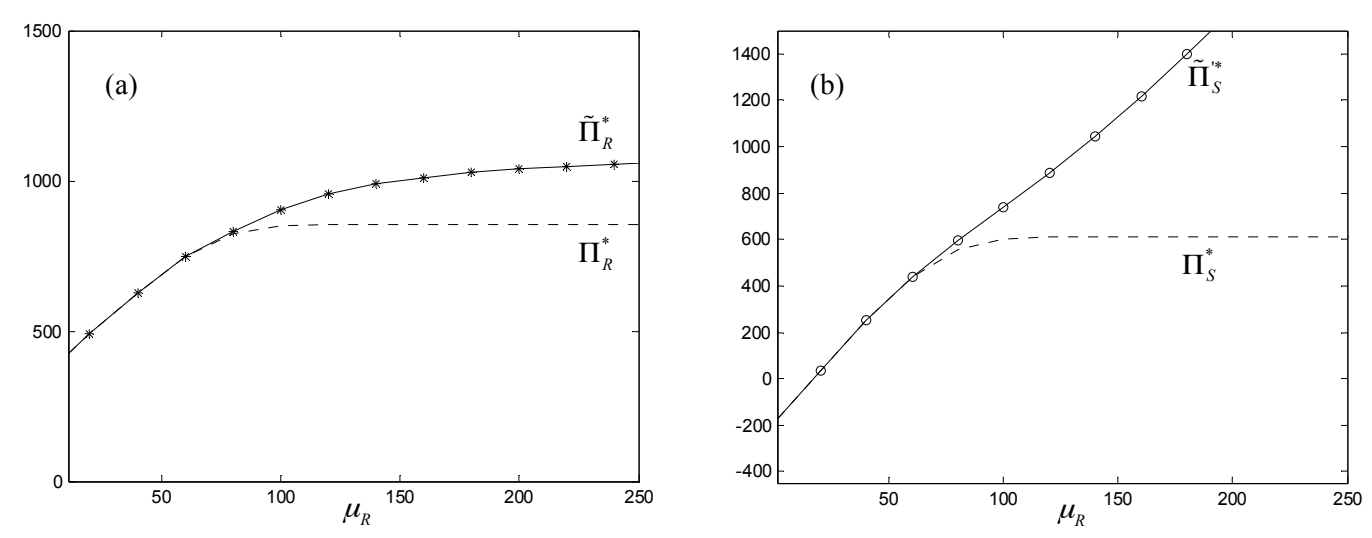

Note: $\quad p_{S}=15 ; c_{k}=6 ; \varepsilon \sim N(0,20) ; c=4 ; T_{0}=0.9 ; \mu_{0}=100 ; \alpha=0.3 ; p_{R}=20$

Figure 10. Retailer and supplier's profits.

Because both the retailer and supplier benefit from the proposed contract, we examine the performances of the entire supply chain in the contract. If the information is symmetric, the supply chain thereby becomes to be centralised. We let $\Pi_{S}^{*}$ denote the real profit under the centralised pattern. In Figure $11 \Pi^{*}, \widetilde{\Pi}_{R}^{*}+\widetilde{\Pi}_{S}^{*}$ and $\Pi_{R}^{*}+\Pi_{S}^{\prime *}$ denote the supply chain's real profit in the centralised, contract and decentralised patterns, respectively. In this experiment, the optimal material quantity in the decentralised pattern is 102. Therefore, the expected profit of supply chain increases with the market demand and comes up to 1262 when real market demand is more than 200. Note that the retailer knows the real market information and encourages the supplier to prepare a large production ability by sharing part of material cost. Therefore, the profit in the contract pattern $\widetilde{\Pi}_{R}^{*}+\widetilde{\Pi}_{S}^{\prime *}$ is no less than in the decentralised pattern $\Pi_{R}^{*}+\Pi_{S}^{\prime *}$. Compared with the profit in the decentralised pattern, the contract performs much better than the decentralised pattern when market demand is large than its historical value. 


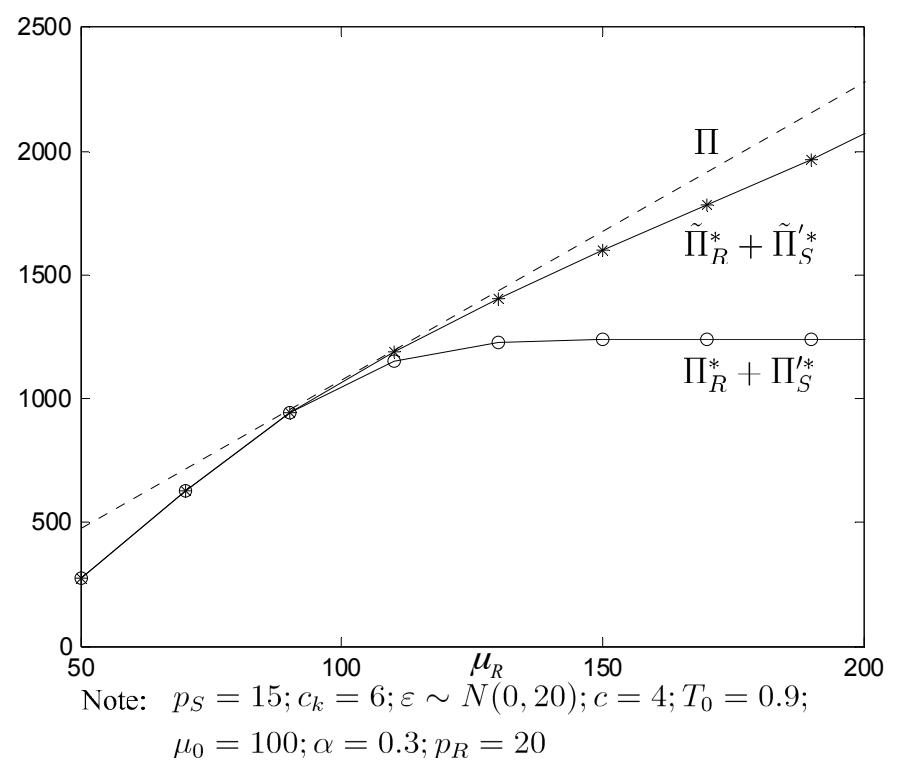

Figure 11. The profit of the supply chain performance in different patterns.

\section{Conclusions and Future Research Directions}

In a retailer-dominated supply chain, the retailer and supplier trade on an EDI-type system, where all soft-orders are cancellable. The retailer occupies the market demand information since she is closer to the market. After the retailer places a soft-order, the supplier relies on the order and historical demand to plan his production and prepare production materials. The reliance is specified by trust and we formulate the supplier's trust as a function of his intuition and the retailer's reputation. We prove that a retailer with low reputation can also earn high trust if his order refers to a supplier's positive intuition. Meanwhile, we also find that it takes a great deal of trust-positive efforts to earn trust. It is observed that the retailer and the supplier are proven to value trust differently, and the retailer's reputations and the supplier's intuitions have great influences on their profits. We find that their decisions are independent with the retailer's order and there is some potential loss for both of them. In order to achieve a 'win-win' sustainable trade, regulation mechanism with trust-embedded binding contract is proposed to align supply chain partners' objectives.

Literatures on trust in supply chain information sharing are few, investigating trust in information sharing offers many potential research opportunities. There are at least two major potential research directions in future. Since retailer's trustworthiness updates with new experiences over time, she might be less motivated to distort her demand information by soft-orders in multi-period transaction. Thus, one potential research direction is to extend our work to multi-period transaction problems. Another potential research direction is to study trust-embedded decisions within more complex decision situations. For example, extending our work to business with multiple tiers or more parallel partners is helpful to fit more situations. Because distrusting is inherently linked to perceived risk, it is also worthwhile to investigate the distrust-induced risk management in information sharing. In short, trust plays a more important role in information sharing and the related research opportunities are boundless.

Acknowledgments: This work was supported in part by the National Natural Science Foundation of China (No. 71501128, 71371123, 71131005 and 71632008), Specialized Research Fund for the Doctoral Program of Higher Education of China (20120073110029), Interdiscipline Foundation of Shanghai Jiao Tong University (No. 15JCZY05 and 11JCZ02), the Shandong Natural Science Foundation (No. 2015ZRB019HR), and Europe-China High Value Engineering Network (EC-HVEN Project Number: 295130). The authors thank Chin Hon Tan at National University of Singapore for his valuable suggestions in the conception of the paper.

Author Contributions: All authors contributed substantially to the conception of the paper and contribute equally in formulating models and giving analysis. 
Conflicts of Interest: The authors declare no conflict of interest.

\section{Appendix A}

Proof of Theorem 1. The retailer and supplier's profits functions under the decentralized pattern are,

$$
\begin{gathered}
\Pi_{R}=\underset{\varepsilon}{E}\left[\left(p_{R}-p_{S}\right) \min \left(Q, \mu_{R}+\varepsilon\right)\right] \\
\Pi_{S}=\underset{\varepsilon}{E}\left[\left(p_{S}-c\right) \min \left(Q, \mu_{S}+\varepsilon\right)-c_{k} Q\right]
\end{gathered}
$$

For a given $\mu_{R S}$, we have $\mu_{S}=T \mu_{R S}+(1-T) \mu_{0}$, where $T=T_{0} \alpha^{\frac{\left|\mu_{R S}-\mu_{0}\right|}{\mu_{0}}}$ (Equation (1)). We introduce $\mu_{S}$ into Equation (A2) and obtain,

$$
\begin{aligned}
Q^{*} & =\underset{Q}{\operatorname{argmax}} \Pi_{S}(Q) \\
& =T \mu_{R S}+(1-T) \mu_{0}+\Gamma^{-1}\left(\frac{p_{S}-c-c_{k}}{p_{S}-c}\right) \\
& =\mu_{S}+\Gamma^{-1}\left(\frac{p_{S}-c-c_{k}}{p_{S}-c}\right)
\end{aligned}
$$

Accordingly, we find that $\Pi_{R}$ increases with $Q$ from Equation (A1). Since $\Gamma^{-1}\left(\frac{p_{S}-c-c_{k}}{p_{S}-c}\right)$ is a constant, we obtain,

$$
\mu_{R S}^{*}=\underset{\mu_{R S}}{\operatorname{argmax}}\left(\Pi_{R}\right)=\underset{\mu_{R S}}{\operatorname{argmax}} Q=\underset{\mu_{R S}}{\operatorname{argmax}} \mu_{S}
$$

According to Equation (A4), we obtain $\mu_{R S}^{*}=\mu_{0}-\mu_{0} / \operatorname{Ln} \alpha$. Thus, $Q^{*}=\mu_{S}^{*}+\Gamma^{-1}\left(\frac{p_{S}-c-c_{k}}{p_{S}-c}\right)=$ $\Gamma^{-1}\left(\frac{p_{S}-c-c_{k}}{p_{S}-c}\right)+\mu_{0}-\frac{\mu_{0} T_{0}}{e \operatorname{Ln} \alpha}$.

Proof of Corollary 1. The equation $T=T_{0}$ is a special case of $T=T_{0} \alpha^{\frac{\left|\mu_{R S}-\mu_{0}\right|}{\mu_{0}}}$ when $\alpha=1$. Introducing $\alpha=1$ into $\mu_{R S}^{*}$ (Theorem 1 ), we find $\mu_{R S}^{*} \rightarrow+\infty$. That is to say, we have $\mu_{R S}^{*} \rightarrow+\infty$ when $T=T_{0}$. The result indicates that the retailer tries to over order as much as she could. Because of the retailer's intention of overstating, her shared information is totally non-reliable to the supplier. Thus, the supplier only relies on the historical demand information $\mu_{0}$ in decision-making, which indicates $\mu_{S}^{*}=\mu_{0}$.

Introducing $\mu_{S}^{*}$ into Equation (4), we have:

$$
\Pi_{S}=\underset{\varepsilon}{E}\left[\left(p_{S}-c\right) \min \left(Q, \mu_{S}+\varepsilon\right)-c_{k} Q\right]
$$

The optimal $Q$ by maximizing $\Pi_{S}$ is calculated as

$$
Q^{*}=\mu_{0}+\Gamma^{-1}\left(\frac{p_{S}-c-c_{k}}{p_{S}-c}\right)
$$

Proof of Proposition 1. Let $\left\{\mathrm{m}, \mu_{R S}, Q\right\}=\left\{0, \mu_{0}\left(1-\frac{1}{\operatorname{Ln\alpha }}\right), \Gamma^{-1}\left(\frac{p_{S}-c-c_{k}}{p_{S}-c}\right)+\mu_{0}-\frac{\mu_{0} T_{0}}{e \operatorname{Ln} \alpha}\right\}$, we obtain,

$$
\begin{aligned}
& \widetilde{\Pi}_{S}=\underset{\varepsilon}{E}\left[\left(p_{S}-c\right) \min \left(\Gamma^{-1}\left(\frac{p_{S}-c-c_{k}}{p_{S}-c}\right)+\mu_{0}-\frac{\mu_{0} T_{0}}{e L n \alpha}, \mu_{S}+\varepsilon\right)\right. \\
& \left.\quad-c_{k}\left(\Gamma^{-1}\left(\frac{p_{S}-c-c_{k}}{p_{S}-c}\right)+\mu_{0}-\frac{\mu_{0} T_{0}}{e L n \alpha}\right)+m\left(\mu_{0}\left(1-\frac{1}{L n \alpha}\right)\right)\right] \\
& \Rightarrow \widetilde{\Pi}_{S}=\Pi_{S}^{*} \\
& \widetilde{\Pi}_{R}=\underset{\varepsilon}{E}\left[\left(p_{R}-p_{S}\right) \min \left(\Gamma^{-1}\left(\frac{p_{S}-c-c_{k}}{p_{S}-c}\right)+\mu_{0}-\frac{\mu_{0} T_{0}}{e L n \alpha}, \mu_{R}+\varepsilon\right)\right] \\
& \Rightarrow \widetilde{\Pi}_{R}=\Pi_{R}^{*}
\end{aligned}
$$

Therefore, $\left\{\mathrm{m}, \mu_{R S}, Q\right\}=\left\{0, \mu_{0}\left(1-\frac{1}{\operatorname{Ln} \alpha}\right), \Gamma^{-1}\left(\frac{p_{S}-c-c_{k}}{p_{S}-c}\right)+\mu_{0}-\frac{\mu_{0} T_{0}}{e \operatorname{Ln} \alpha}\right\}$ satisfies the constraints of the objective model. So that the solution of Equations (9) and (10) exists. 
Proof of Proposition 2. We simplify the bind constraint $\widetilde{H}_{R}\left(Q, \mu_{R S}\right)-m \mu_{R S} \geq \Pi_{R}^{*}$ and get $m \leq \frac{\widetilde{H}_{R}\left(Q, \mu_{R S}\right)-\Pi_{R}^{*}}{\mu_{R S}}=\frac{\widetilde{H}_{R}\left(\mu_{R S}, \mu_{R S}\right)-\Pi_{R}^{*}}{\mu_{R S}}$. However, the supplier's least acceptable shared cost for binding the order is $m \geq \frac{\Pi_{S}^{*}\left(Q^{*}\right)-\widetilde{H}_{S}\left(\mu_{R S}\right)}{\mu_{R S}}$. Therefore, we calculate the retailer and the supplier's solutions in the following two scenarios.

$$
\text { Scenario 1. } \frac{\widetilde{H}_{R}\left(\mu_{R S}, \mu_{R S}\right)-\Pi_{R}^{*}}{\mu_{R S}} \geq \frac{\Pi_{S}^{*}\left(Q^{*}\right)-\widetilde{H}_{S}\left(\mu_{R S}\right)}{\mu_{R S}}
$$

$\frac{\widetilde{H}_{R}\left(\mu_{R S}, \mu_{R S}\right)-\Pi_{R}^{*}}{\mu_{R S}} \geq \frac{\Pi_{S}^{*}\left(Q^{*}\right)-\widetilde{H}_{S}\left(\mu_{R S}\right)}{\mu_{R S}}$ indicates that the retailer's maximum tolerated shared cost is acceptable by the supplier. Since the retailer denotes the trade, the retailer provided shared cost for per ordered quantity is $\widetilde{\mathrm{m}}^{*}=\frac{\Pi_{S}^{*}\left(\mathrm{Q}^{*}\right)-\widetilde{H}_{S}\left(\mu_{R S}\right)}{\mu_{R S}}$. Therefore, according Equation (5), the retailer's optimal ordered quantity is $\widetilde{\mu}_{R S}^{*}=\underset{\mu_{R S}}{\operatorname{argmax}} \widetilde{\Pi}_{R}$. Since the supplier agrees to bind the retailer's order, his optimal material quantity is $\widetilde{Q}^{*}=\mu_{R S}$.

$$
\text { Scenario 2. } \frac{\widetilde{H}_{R}\left(\mu_{R S}, \mu_{R S}\right)-\Pi_{R}^{*}}{\mu_{R S}}<\frac{\Pi_{S}^{*}\left(Q^{*}\right)-\widetilde{H}_{S}\left(\mu_{R S}\right)}{\mu_{R S}}
$$

At this situation, the retailer's maximum tolerated shared cost is less than the supplier's tolerated shared cost. Thus, the supplier will not bind the ordered quantity. Therefore, in this case, the retailer's order is not bound. According to Equations (4) and (5), we have their solutions $\left\{\widetilde{\mathrm{m}}^{*}, \widetilde{\mu}_{R S}^{*}, \widetilde{Q}^{*}\right\}=$ $\left\{0, \mu_{0}\left(1-\frac{1}{\operatorname{Ln\alpha }}\right), \Gamma^{-1}\left(\frac{p_{S}-c-c_{k}}{p_{S}-c}\right)+\mu_{0}-\frac{\mu_{0} T_{0}}{e L n \alpha}\right\}$

To summarize scenario 1 and scenario 2, we obtain,

$$
\begin{aligned}
& \widetilde{\mathrm{m}}^{*}=\left\{\begin{array}{l}
\frac{\Pi_{S}^{*}\left(Q^{*}\right)-\widetilde{H}_{S}\left(\mu_{R S}\right)}{\mu_{R S}} \\
0 \text { otherwise }
\end{array} \text { if } \widetilde{H}_{R}\left(\mu_{R S}, \mu_{R S}\right)-\Pi_{R}^{*} \geq \Pi_{S}^{*}\left(Q^{*}\right)-\widetilde{H}_{S}\left(\mu_{R S}\right)\right. \\
& \widetilde{\mu}_{R S}^{*}=\left\{\begin{array}{l}
\underset{\mu_{R S}}{\operatorname{argmax}} \widetilde{\Pi}_{R} \text { if } \widetilde{H}_{R}\left(\mu_{R S}, \mu_{R S}\right)-\Pi_{R}^{*} \geq \Pi_{S}^{*}\left(Q^{*}\right)-\widetilde{H}_{S}\left(\mu_{R S}\right) \\
\mu_{0}\left(1-\frac{1}{L n \alpha}\right) \text { otherwise }
\end{array}\right. \\
& \widetilde{Q}^{*}=\left\{\begin{array}{l}
\mu_{R S} \text { if } \widetilde{H}_{R}\left(\mu_{R S}, \mu_{R S}\right)-\Pi_{R}^{*} \geq \Pi_{S}^{*}\left(Q^{*}\right)-\widetilde{H}_{S}\left(\mu_{R S}\right) \\
\Gamma^{-1}\left(\frac{p_{S}-c-c_{k}}{p_{S}-c}\right)+\mu_{0}-\frac{\mu_{0} T_{0}}{e L n \alpha} \quad \text { otherwise }
\end{array}\right.
\end{aligned}
$$

where

$$
Q^{*}=\Gamma^{-1}\left(\frac{p_{S}-c-c_{k}}{p_{S}-c}\right)+T_{0} \alpha^{\frac{\left|\mu_{R S}-\mu_{0}\right|}{\mu_{0}}} \mu_{0}-T_{0} \alpha^{\frac{\left|\mu_{R S}-\mu_{0}\right|}{\mu_{0}}} \mu_{R S}+\mu_{R S}
$$

\section{References}

1. Aviv, Y. The effect of collaborative forecasting on supply chain performance. Manag. Sci. 2001, 47, 1326-1343. [CrossRef]

2. Holmström, J.; Främling, K.; Kaipia, R.; Saranen, J. Collaborative planning forecasting and replenishment: New solutions needed for mass collaboration. Supply Chain Manag. 2002, 7, 136-145. [CrossRef]

3. Martino, G.; Fera, M.; Iannone, R.; Miranda, S. Proposal of a multi-method decision support system for the fashion retail industry. In Business Models and ICT Technologies for the Fashion Supply Chain; Springer: Cham, Switzerland, 2016; pp. 187-199.

4. Martino, G.; Iannnone, R.; Fera, M.; Miranda, S.; Riemma, S. Fashion retailing: A framework for supply chain optimization. Uncertain Supply Chain Manag. 2017, 5, 243-272. [CrossRef]

5. Christopher, D. A Comparison of Supplier Enablement around the World; Aberdeem Group: Boston, MA, USA, 2008.

6. Özer, Ö.; Wei, W. Strategic commitments for an optimal capacity decision under asymmetric forecast information. Manag. Sci. 2006, 52, 1238-1257. [CrossRef]

7. Özer, Ö.; Zheng, Y.C.; Chen, K.Y. Trust in forecast information sharing. Manag. Sci. 2011, 57, 1111-1137. [CrossRef] 
8. Lu, B.; Zeng, Q.; Fan, W. Examining macro-sources of institution-based trust in social commerce marketplaces: An empirical study. Electron. Commer. Res. Appl. 2016, 20, 116-131. [CrossRef]

9. Han, G.; Dong, M. Trust-embedded coordination in supply chain information sharing. Int. J. Prod. Res. 2015, 53, 5624-5639. [CrossRef]

10. Kartik, N. Information Transmission with Cheap and Almost-Cheap-Talk. Available online: http:/ / politics. as.nyu.edu/docs/IO/4739/katrik_f04.pdf (accessed on 30 May 2017).

11. Adamopoulou, A.A.; Symeonidis, A.L. A simulation testbed for analyzing trust and reputation mechanisms in unreliable online markets. Electron. Commer. Res. Appl. 2014, 13, 368-386. [CrossRef]

12. Nilashi, M.; Jannach, D.; bin Ibrahim, O.; Esfahani, M.D.; Ahmadi, H. Recommendation quality, transparency, and website quality for trust-building in recommendation agents. Electron. Commer. Res. Appl. 2016, 19, 70-84. [CrossRef]

13. Rousseau, D.M.; Sitkin, S.B.; Burt, R.S.; Camerer, C.F. Not so different after all: A cross-discipline view of Trust. Acad. Manag. Rev. 1998, 23, 393-404. [CrossRef]

14. Shukla, N.; Choudhary, A.K.; Prakash, P.K.S.; Fernandes, K.J.; Tiwari, M.K. Algorithm portfolios for logistics optimization considering stochastic demands and mobility allowance. Int. J. Prod. Econ. 2013, 141, 146-166. [CrossRef]

15. Fera, M.; Fruggiero, F.; Lambiase, A.; Macchiaroli, R.; Miranda, S. The role of uncertainty in supply chains under dynamic modeling. Int. J. Ind. Eng. Comput. 2017, 8, 119-140. [CrossRef]

16. Petrovic, D. Simulation of supply chain behaviour and performance in an uncertain environment. Int. J. Prod. Econ. 2001, 71, 429-438. [CrossRef]

17. Chen, M.C.; Yang, T.; Li, H.C. Evaluating the supply chain performance of IT-based inter-enterprise collaboration. Inf. Manag. 2007, 44, 524-534. [CrossRef]

18. Moon, Y.; Kwon, C. Online advertisement service pricing and an option contract. Electron. Commer. Res. Appl. 2011, 10, 38-48. [CrossRef]

19. Ren, Z.J.; Cohen, M.A.; Ho, T.H.; Terwiesch, C. Information sharing in a long-term supply chain relationship: The role of customer review strategy. Oper. Res. 2010, 58, 81-93. [CrossRef]

20. Lewis, G.; Bajari, P. Moral hazard, incentive contracts, and risk: Evidence from procurement. Rev. Econ. Stud. 2014, 81, 1201-1228. [CrossRef]

21. Bhattacharyya, S.; Lafontaine, F. Double-sided moral hazard and the nature of share contracts. RAND J. Econ. 1995, 26, 761-781. [CrossRef]

22. Al-Qirim, N. The adoption of eCommerce communications and applications technologies in small businesses in New Zealand. Electron. Commer. Res. Appl. 2008, 6, 462-473. [CrossRef]

23. Park, I.U. Cheap talk referrals of differentiated experts in repeated relationship. RAND J. Econ. 2005, 36, 391-411. [CrossRef]

24. Lee, H.L.; Padmanabhan, V.; Whang, S. Information distortion in a supply chain: The bullwhip effect. Manag. Sci. 1997, 43, 546-558. [CrossRef]

25. Cohen, M.; Ho, T.; Ren, Z.; Terwiesch, Z. Measuring imputed cost in the semiconductor equipment supply chain. Manag. Sci. 2003, 49, 1653-1670. [CrossRef]

26. Blumenschein, K.; Blomquist, G.C.; Johannesson, M.; Horn, N.; Freeman, P. Eliciting willingness to pay without bias: Evidence from a field experiment. Econ. J. 2008, 118, 114-137. [CrossRef]

27. Dodgson, M.; Rothwell, R. The Handbook of Industrial Innovation; Edward Elgar Publishing: Cheltenham, UK, 1995.

28. Rouibah, K.; Lowry, P.B.; Hwang, Y. The effects of perceived enjoyment and perceived risks on trust formation and intentions to use online payment systems: New perspectives from an Arab country. Electron. Commer. Res. Appl. 2016, 19, 33-43. [CrossRef]

29. Moody, G.D.; Galletta, D.F.; Lowry, P.B. When trust and distrust collide online: The engenderment and role of consumer ambivalence in online consumer behavior. Electron. Commer. Res. Appl. 2014, 13, $266-282$. [CrossRef]

30. Doney, P.M.; Cannon, J.P. An examination of the nature of trust in buyer-seller relationships. J. Mark. 1997, 61, 35-51. [CrossRef]

31. Ebrahim-Khanjari, N.; Hopp, W.; Iravani, S.M. Trust and information sharing in supply chains. Prod. Oper. Manag. 2012, 21, 444-464. [CrossRef] 
32. Fu, X.; Dong, M.; Liu, S.; Han, G. Trust based decisions in supply chains with an agent. Decis. Support Syst. 2016, 82, 35-46. [CrossRef]

33. Utz, S.; Kerkhof, P.; van den Bos, J. Consumers rule: How consumer reviews influence perceived trustworthiness of online stores. Electron. Commer. Res. Appl. 2012, 11, 49-58. [CrossRef]

34. Han, G.; Dong, M.; Sun, Q. Managing distrust-induced risk with deposit in supply chain contract decisions. Sci. World J. 2014, 2014, 961394. [CrossRef] [PubMed]

35. Liu, X.; Datta, A.; Rzadca, K. Trust beyond reputation: A computational trust model based on stereotypes. Electron. Commer. Res. Appl. 2013, 12, 24-39. [CrossRef]

36. Sriram, M.S. Information asymmetry and trust: A framework for studying microfinance in India. Vikalpa 2005, 30, 77 .

37. Schweitzer, M.E.; Cachon, G.P. Decision bias in the newsvendor problem with a known demand distribution: Experimental evidence. Manag. Sci. 2000, 46, 404-420. [CrossRef]

38. Fisher, M.; Raman, A. Reducing the cost of demand uncertainty through accurate response to early sales. Oper. Res. 1996, 44, 87-99. [CrossRef]

39. Schleifer, A. LL Bean, Inc.: Item Forecasting and Inventory Management; Harvard Business School: Boston, MA, USA, 1992.

40. Balakrishnan, K. Exponential Distribution: Theory, Methods and Applications; CRC Press: Boca Raton, FL, USA, 1996.

41. Everitt, B.S.; Hand, D.J. Monographs on Applied Probability and Statistics. In Finite Mixture Distributions; Chapman and Hall: London, UK, 1981.

42. Aron, A.R.; Shohamy, D.; Clark, J.; Myers, C.; Gluck, M.A.; Poldrack, R.A. Human midbrain sensitivity to cognitive feedback and uncertainty during classification learning. J. Neurophysiol. 2004, 92, 1144-1152. [CrossRef] [PubMed]

43. Zou, X.; Dai, Y.S.; Pan, Y. Trust and Security in Collaborative Computing; World Scientific Publishing and Imperial College Press: Singapore, 2008.

44. Tan, Z. On profile likelihood for exponential tilt mixture models. Biometrika 2009, 96, 229-236. [CrossRef]

45. Clemen, R.T.; Winkler, R.L. Combining probability distributions from experts in risk analysis. Risk Anal. 1999, 19, 187-203. [CrossRef]

46. Neuburger, R. Electronic Data Interchange; Deutscher Universitäts Verlag: Wiesbaden, Germany, 1994.

47. U.S. Securities and Exchange Commission. Available online: https://www.sec.gov/Archives/edgar/data/ 931336/000119312513437081/d598080dex101.htm (accessed on 15 May 2017).

48. Thonemann, U.W. Improving supply-chain performance by sharing advance demand information. Eur. J. Oper. Res. 2002, 142, 81-107. [CrossRef]

49. Ding, H.; Guo, B.; Liu, Z. Information sharing and profit allotment based on supply chain cooperation. Int. J. Prod. Econ. 2011, 133, 70-79. [CrossRef]

50. Baymard Institute. Cart Abandonment Rate Statistics. Available online: http://baymard.com/lists/cartabandonment-rate (accessed on 15 December 2015).

51. Meier, M.; Campisano, S.; Deaves, T.; Gingerich, S.; Oke, K. Tracking EDI Documents with Information from Multiple Sources. U.S. Patent Application No. 10/378,343, 24 July 2003.

52. Ross, J.W.; Beath, C.M.; Goodhue, D.L. Develop long-term competitiveness through IT assets. MIT Sloan Manag. Rev. 1996, 38, 31.

53. Uber. Available online: https://www.uber.com/drive/rewards/ (accessed on 15 May 2017).

54. Hattori, R.A.; Lapidus, T. Collaboration, trust and innovative change. J. Chang. Manag. 2004, 4, 97-104. [CrossRef]

55. Kim, D.J.; Ferrin, D.L.; Rao, H.R. A Trust-based consumer decision-making model in electronic commerce: The Role of Trust, Perceived Risk, and Their Antecedents. Decis. Support Syst. 2008, 44, 544-564. [CrossRef]

56. Resnick, P.; Zeckhauser, R.; Swanson, J.; Lockwood, K. The value of reputation on eBay: A controlled experiment. Exp. Econ. 2006, 9, 79-101. [CrossRef]

57. Jilovec, N. EDI, UCCnet, and RFID: Synchronizing the Supply Chain; System iNetwork; 29th Street Press: Loveland, CO, USA, 2004. 